\title{
Nrf2 and Ferroptosis: A New Research Direction for Neurodegenerative Diseases
}

\author{
Xiaohua Song and Dingxin Long* \\ School of Public Health, University of South China, Hengyang, China
}

Ferroptosis is a kind of regulated cell death (RCD) caused by the redox state disorder of intracellular microenvironment controlled by glutathione (GSH) peroxidase 4 (GPX4), which is inhibited by iron chelators and lipophilic antioxidants. In addition to classical regulatory mechanisms, new regulatory factors for ferroptosis have been discovered in recent years, such as the P53 pathway, the activating transcription factor (ATF)3/4 pathway, Beclin 1 (BECN1) pathway, and some non-coding RNA. Ferroptosis is closely related to cancer treatment, neurodegenerative diseases, ischemia-reperfusion of organ, neurotoxicity, and others, in particular, in the field of neurodegenerative diseases treatment has aroused people's interest. The nuclear factor E2 related factor 2 (Nrf2/NFE2L2) has been proved to play a key role in neurodegenerative

Edited by: David Pozo,

University of Seville, Spain

Reviewed by:

Carmela Conte,

University of Perugia, Italy Veronica Perez De La Cruz, Instituto Nacional de Neurología y Neurocirugía Manuel Velasco Suárez,

Mexico

*Correspondence: Dingxin Long dxlong99@163.com

Specialty section: This article was submitted to

Neurodegeneration, a section of the journal Frontiers in Neuroscience

Received: 11 July 2019 Accepted: 09 March 2020

Published: 21 April 2020

Citation:

Song $X$ and Long D (2020) Nif2 and Ferroptosis: A New Research

Direction for Neurodegenerative Diseases. Front. Neurosci. 14:267.

doi: 10.3389/fnins.2020.00267 disease treatment and ferroptosis regulation. Ferroptosis promotes the progression of neurodegenerative diseases, while the expression of Nrf2 and its target genes ( $\mathrm{Ho}-1$, Nqo-1, and Trx) has been declined with aging; therefore, there is still insufficient evidence for ferroptosis and Nrf2 regulatory networks in the field of neurodegenerative diseases. In this review, we will provide a brief overview of ferroptosis regulatory mechanisms, as well as an emphasis on the mechanism of Nrf2 regulating ferroptosis. We also highlight the role of ferroptosis and Nrf2 during the process of neurodegenerative diseases and investigate a theoretical basis for further research on the relationship between Nrf2 and ferroptosis in the process of neurodegenerative diseases treatment.

\footnotetext{
Keywords: neurodegenerative diseases, ferroptosis, nuclear factor E2 related factor 2 (Nrf2/NFE2L2), glutathione peroxidase 4 (GPX4), regulation mechanism
}

\section{INTRODUCTION}

Programed cell death is critical to all aspects of mammalian growth and development, homeostatic regulation, and disease control and is closely integrated with other biological processes to sustain life. Ferroptosis is a process that is different from apoptosis, pyroptosis, necroptosis, and other programed cell death (Dixon et al., 2012). In 2018, The International Cell Death Nomenclature Committee defined ferroptosis as a form of regulated cell death (RCD) caused by oxidative alterations in the intracellular microenvironment controlled by glutathione (GSH) peroxidase 4 (GPX4) constitutively, and it can be inhibited by iron chelators and lipophilic antioxidants (Galluzzi et al., 2018). Morphologically, the most important morphological changes of ferroptosis are mitochondria, including mitochondrial contraction, electron-dense mass formation 
under ultrastructure, reduction or disappearance of mitochondrial cristae, changes in membrane potential, and rupture of mitochondria outer membrane (Vanden Berghe et al., 2014). In addition to the final key morphological changes, the increase of free iron and lipid peroxidation are also important features of ferroptosis, and it is also related to the instability of the plasma membrane, disrupted protein stability, and cytoskeleton rearrangement, leading to the obvious "balloon" phenotype of the cells (Louandre et al., 2013; Gao et al., 2015; Agmon et al., 2018; Dodson et al., 2019), and finally caused cell death. In recent years, with the rapid development of ferroptosis-related research in many fields, it has made a great impact on the fields of cancer therapy, neurodegenerative diseases, ischemia and reperfusion, etc. After the formal concept of ferroptosis, the researchers began to believe that ferroptosis is the main driver of neuronal death in diseases such as Parkinson's disease (PD), Alzheimer's disease (AD), and Huntington's disease (HD) (Guiney et al., 2017; Morris et al., 2018; Mi et al., 2019).

Ferroptosis is characterized by the massive accumulation of fatal intracellular lipid reactive oxygen species (ROS) when the antioxidant capacity of cells decreases (Dixon et al., 2012). Studies have found that ferroptosis is regulated by GPX4 (system Xc-) (Dixon et al., 2012; Friedmann Angeli et al., 2014; Yang et al., 2014), lipid synthesis (Doll et al., 2017; Gao and Jiang, 2018), iron metabolism (Gao et al., 2016; Hou et al., 2016; Hassannia et al., 2019), the mevalonate pathway (Shimada et al., 2016), Nrf2 (or NFE2L2) pathway (Abdalkader et al., 2018; Kerins and Ooi, 2018), and other factors (Luo et al., 2018; Wang et al., 2019c; Ye et al., 2019). Among them, the regulatory effect of transcription factor nuclear factor E2 related factor 2 (Nrf2/NFE2L2) on ferroptosis has attracted our interest. The basic leucine zipper (bZIP) transcription factor Nrf2/NFE2L2 protects cells from oxidative stress by regulating the endogenous antioxidant response pathway. The activity of $\mathrm{Nrf} 2$ is strictly regulated by Kelch-like ECH-related protein 1 (Keap1); Keap1 not only passively isolates Nrf2 from the cytoplasm but also plays an active role in targeting Nrf2 for ubiquitination and proteasome degradation (Zhang et al., 2004; Furukawa and Xiong, 2005). Nrf2 can directly or indirectly regulate GPX4 protein content (Hayes and Dinkova-Kostova, 2014; Fan et al., 2017; Dodson et al., 2019; Zhang et al., 2019), intracellular free iron content (Agyeman et al., 2012; Sun et al., 2016b; Shin et al., 2018), mitochondrial function (Merry and Ristow, 2016; Navarro et al., 2017), nicotinamide adenine dinucleotide hydro-phosphoric acid (NAPDH) regeneration (Abdalkader et al., 2018), etc., thereby regulating ferroptosis process. Of note, many studies found that Nrf2 is expressed in the central nervous system (CNS), neurons, astrocytes, leukocytes, and microglia (Tanaka et al., 2011; Dang et al., 2012; Sandberg et al., 2014), and numerous evidence suggests that Nrf2 plays an important role in the development and treatment of neurodegenerative diseases (Wang et al., 2017; Deng et al., 2019; Jang et al., 2019; Pachón-Angona et al., 2019; Wei et al., 2019). Nrf2 has already acted as a well-known target for neurodegenerative disease treatment (de Oliveira et al., 2018; Muhammad et al., 2019; Wang et al., 2019a) and plays a key role in neuronal resistance to oxidative stress and glutamateinduced excitotoxicity and promotes neuronal degeneration and neuronal survival in acute nerve injury. However, in the field of neurodegenerative diseases, there is insufficient research evidence to show that Nrf2 can protect nerve and its related regulatory factors by regulating the mechanism of ferroptosis.

\section{THE REGULATION NETWORK OF FERROPTOSIS}

\section{The Lipid Peroxidation Pathway for Ferroptosis Regulation}

After years of research, people have a certain understanding of the regulatory network of ferroptosis (Figure 1). There are three main regulatory pathways for ferroptosis. Studies have confirmed that ferroptosis selective preferentially oxidizes specific polyphosphorylated phosphatidylethanolamine (PE)containing polyunsaturated fatty acids (PUFAs), such as arachidonic acid (AA) and epinephrine (Dixon et al., 2015; Kagan et al., 2017), leading to lipid peroxidation in the end, so the lipid peroxidation pathway plays the key role in regulating ferroptosis. Acyl-CoA synthetase long-chain family member 4 (ACSL4), which is a key enzyme that regulates lipid composition, has been shown to contribute to the execution of ferroptosis. During the lipid peroxidation pathway, ACSL4 promotes ferroptosis by producing oxidized $\mathrm{PE}$ at the endoplasmic reticulum (ER)-associated oxygenation center, and ACSL4 catalyzes the attachment of AA or adrenaline (AdA) to produce AA or AdA acyl Co-A derivatives, which is then esterified to PE (AA-PE and AdA-PE) by lysophosphatidylcholine acyltransferase 3 (LPCAT3). Subsequently, AA-PE and AdAPE are oxidized by 15-lipoxygenase (15-LOX) to produce lipid hydroperoxide, which ultimately leads to ferroptosis (Doll et al., 2017; Gao and Jiang, 2018), and further research finds that ferroptosis is initiated by the selective and specific peroxidation of sn2-ETE-PE to sn215HpETE-PE by 15-LOX/PEPB1 complex (Kagan et al., 2017; Wenzel et al., 2017; Anthonymuthu et al., 2018). There are many regulatory factors for ACSL4 expression; recently, researchers found that special protein 1 (Sp1) was a crucial transcription factor that increased ACSL4 transcription by binding to the ACSL4 promoter region to promote ACSL4 expression to enhance ferroptosis (Li Y. et al., 2019). Lipid peroxidation also happened in $\mathrm{p} 53$-mediated ferroptosis. P53 plays a positive role in ferroptosis and identifies coenzyme $\mathrm{A}(\mathrm{CoA})$ as a regulator of this cell death process (Leu et al., 2019). Loss of P53 prevents nuclear accumulation of dipeptidyl-peptidase-4 (DPP4) and thus facilitates plasma membrane-associated DPP4-dependent lipid peroxidation, which finally results in ferroptosis (Xie et al., 2017), and p53 suppresses ferroptosis through the induction of cyclindependent kinase inhibitor 1A (CDKN1A/p21) expression by reduced accumulation of toxic lipid-ROS (Tarangelo et al., 2018; Kang et al., 2019). Arachidonate 12-lipoxygenase (ALOX12) inactivation diminishes p53-mediated ferroptosis induced by ROS stress (Chu et al., 2019). Interestingly, p53 also plays a negative role in ferroptosis regulation. Spermidine/spermine N1-acetyltransferase 1 (SAT1) is a transcription target of p53, SAT1 expression induces lipid peroxidation and sensitizes cells 


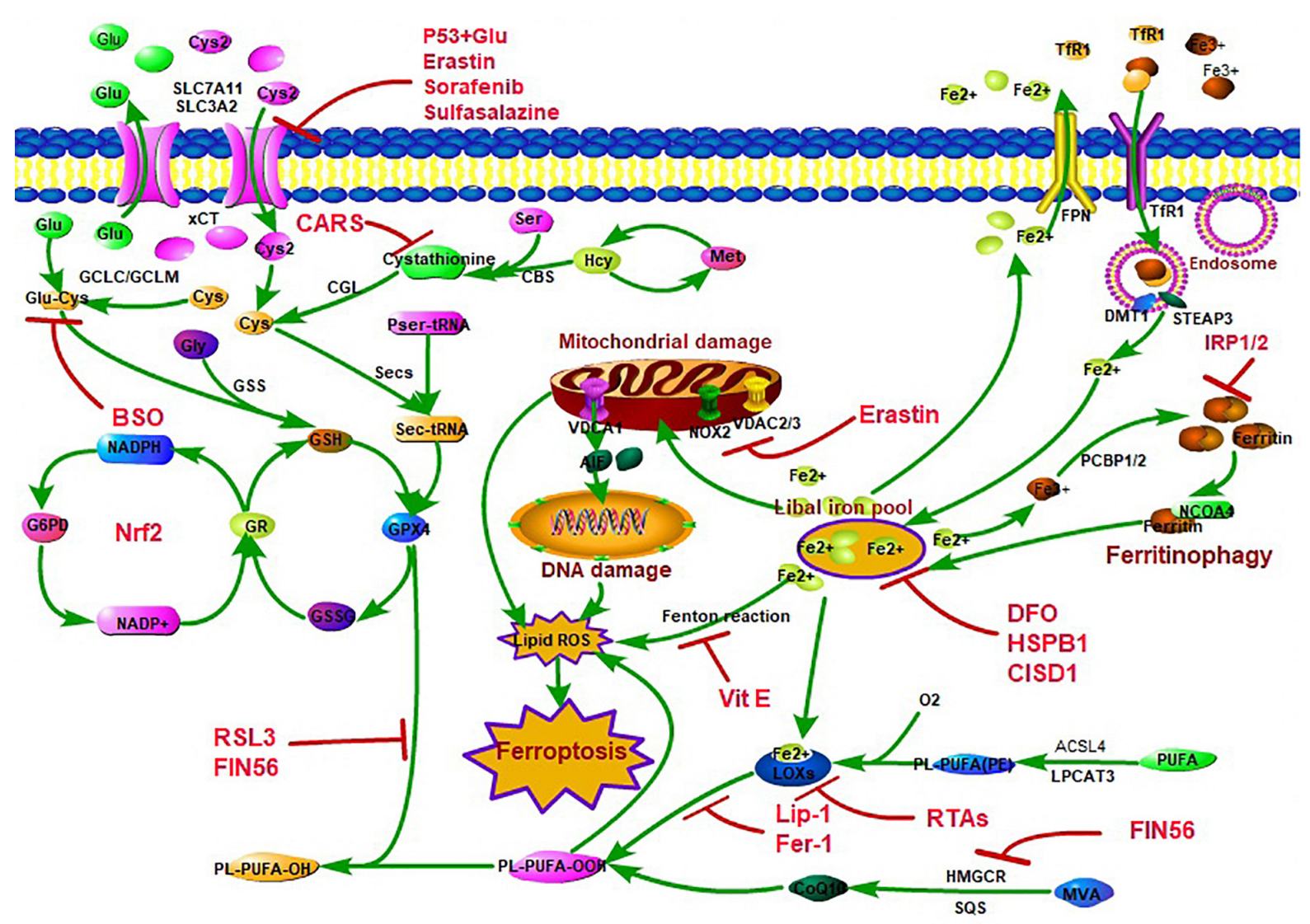

FIGURE 1 | The classic control network of ferroptosis. There are three main characteristics for ferroptosis, including lipid peroxidation, amino acid metabolism disorder, and iron accumulation. The lipid hydroperoxide metabolic pathway is mainly controlled by Acyl-CoA synthetase long-chain family member 4 (ACSL4), Iysophosphatidylcholine acyltransferase (LPCAT3), and lipoxygenases (LOXs). ACSL4 catalyzes the attachment of arachidonic acid (AA) or adrenaline (AdA) to produce AA or AdA acyl Co-A derivatives, which is then esterified to phosphatidylethanolamine (PE) (AA-PE and AdA-PE) by lysophosphatidylcholine acyltransferase 3 (LPCAT3). Subsequently, AA-PE and AdA-PE are oxidized by LOXs to produce lipid hydroperoxide, which ultimately leads to ferroptosis. The amino acid metabolism disorder pathway is mainly owing to glutathione (GSH) peroxidase 4 (GPX4) synthesis and function blocking. GPX4 resists iron and oxygen-dependent lipid peroxidation by converting lipid peroxides (L-OOH) to non-toxic lipids and acts as the key enzyme in ferroptosis regulation. GSH is a cofactor and a synthetic substrate for GPX4 and is required for the lipid repair function of GPX4. GPX4 synthesized by GSH requires the pentose-phosphate pathway to supply ATP [through the nicotinamide adenosine dinucleotide hydro-phosphoric acid (NADPH) cycle]. GSH is synthesized by glutamate (Glu), cysteine (Cys), and glycine (Gly) and consists of ATP-dependent glutamate-cysteine ligase (GCL) and GSH synthetase (GSS) through cystine/glutamate reverse transport system xCT [12-channel transmembrane protein transporter vector family 7 member 11 (SLC7A11)/single-channel transmembrane regulatory protein solute carrier family 3 member 2 (SLC3A2)] or sulfur transfer pathway [methionine (Met)-homocysteine (Hcy)-cysteine (Cys) pathway]. When xCT/sulfur transfer pathway is inhibited, the synthesis of GSH and Cys decreasing, which leads to the inhibition of GPX4 synthesis and function to clear LOOH suppression, eventually leading to lipid peroxidation and inducing ferroptosis. The iron accumulation mainly caused by the loss of control of iron transport [membrane iron transporter (FPN), transfer iron protein receptor 1 (TfR1), divalent metal ion transporter 1 (DMT1)] and iron storage [ferritin, degradation via the nuclear receptor coactivator 4 (NCOA4)-mediated ferritinophagy pathway], leading to an increase in the concentration of iron in the labile iron pool (LIP) and an increase in reactive oxygen species (ROS) through Fenton reaction/mitochondrial damage/LOX function.

to undergo ferroptosis upon ROS-induced stress, while knockout of SAT1 expression or pharmacologically inhibited ALOX15 partially abrogates p53-mediated ferroptosis (Ou et al., 2016).

\section{The Glutathione Peroxidase 4 Synthesis and Function-Related Pathway for Ferroptosis Regulation}

Amino acid metabolism is also crucial for the regulation of ferroptosis (Angeli et al., 2017). GPX4 is a lipid repair enzyme in our body, and GPX4 was identified as a key regulatory factor in ferroptosis (Dixon et al., 2012; Ingold et al., 2018; Forcina and Dixon, 2019). GPX4 resists iron and oxygen-dependent lipid peroxidation by converting lipid peroxides (L-OOH) to non-toxic lipids (Ursini et al., 1985). GSH is a cofactor and a synthetic substrate for GPX4, and it is required for the lipid repair function of GPX4 (Feng and Stockwell, 2018). GSH is an essential intracellular antioxidant synthesized by glutamate, cysteine, and glycine, which is composed of ATP-dependent cytoplasmic enzymes glutamate-cysteine ligase (GCL) and GSH synthetase (GSS) (Stockwell et al., 2017) and cystine/glutamate reverse transport system Xc- [or XCT/12 channel transmembrane 
protein transport protein carrier family 7 member 11 (SLC7A11) mediates the uptake of cystine to exchange the output of glutamate] was identified as the pivotal regulator for GSH synthesis (Hao et al., 2018). Inhibition of system Xc- led to the depletion of cysteine, lacking GSH synthetic substrate, and then impaired the function of antioxidant enzyme GPX4 (Friedmann Angeli et al., 2014; Yang et al., 2014), which finally caused an imbalance of homeostatic oxygen homeostasis, leading to ferroptosis (Dixon et al., 2012). Genomic disruption of xCT via CRISPR-Cas9 proved that the cystine/glutamate exchanger $\mathrm{xCT}$ is essential for amino acid and redox homeostasis in the ferroptosis process (Daher et al., 2019). During the GPX4 synthesis and function-related pathway for ferroptosis regulation, p53 can enhance ferroptosis by inhibiting the expression of SLC7A11 (Jiang et al., 2015; Kang et al., 2019). The histone deubiquitinating enzyme breast cancer 1(BRCA1)-associated protein 1 (BAP1) also inhibits SLC7A11 by reducing $\mathrm{H} 2 \mathrm{~A}$ ubiquitination (H2Aub) on the SLC7A11 promoter (Zhang et al., 2019). Cytokine signaling 1 (SOCS1) is required for p53 activation and the regulation of cellular senescence, and SOCS1 is sufficient to regulate the expression of p53 target genes and sensitized cells to ferroptosis by reducing the expression of the cystine transporter SLC7A11 and the levels of GSH (SaintGermain et al., 2017). Histone H2B on lysine 120 (H2Bub1) is an epigenetic mark generally associated with transcriptional activation, and $\mathrm{H} 2 \mathrm{Bub} 1$ epigenetically activates the expression of SLC7A11, but p53 decreases H2Bub1 occupancy on the SLC7A11 gene regulatory region and represses the expression of SLC7A11 during ferroptosis process (Wang et al., 2019f). Recently, the OTU domain, ubiquitin aldehyde binding 1 (OTUB1) was demonstrated as a key factor in modulating SLC7A11 stability. OTUB1 directly interacted with and stabilized SLC7A11; conversely, OTUB1 knockdown diminished SLC7A11 levels, finally inducing ferroptosis (Liu et al., 2019). Activating transcription factor (ATF) 3 is a member of the ATF/cAMP response element binding protein (CREB) family of transcription factors, and its expression is rapidly induced by a wide range of cellular stresses, including DNA damage, oxidative stress, and cell injury. ATF3 achieved this activity through binding to the SLC7A11 promoter and repressing SLC7A11 expression in a p53independent manner (Wang et al., 2019b). ATP-binding cassette, sub-family C (CFTR/MRP), member 1 (ABCC1)/multidrug resistance protein 1 (MRP1) was confirmed to mediate GSH efflux from the cell (Cole, 2014). High levels of MRP1 expression could mediate GSH efflux, thus affecting the synthesis of GPX4, and promote collateral sensitivity to ferroptosis-inducing agents in the end (Cao et al., 2019). When investigated, ferroptosis in CD8 + T cells that is activated by cancer immunotherapy, the interferon-gamma (IFN $\gamma$ ), downregulates the expression of SLC3A2 and SLC7A11, impairs the uptake of cystine by tumor cells, and as a consequence, promotes tumor cell lipid peroxidation and ferroptosis (Wang et al., 2019d). Therefore, the stability of SLC7A11 plays a crucial role in GPX4 synthesis and finally regulates ferroptosis.

The function of GPX4 is equally important for the regulation of ferroptosis. ATF4 is a 351-amino acid cAMP-response element binding protein that belongs to the CREB-2 family of proteins. ATF4 resulted in the induction of heat shock protein 70 family protein 5 (HSPA5), which in turn bound GPX4 and protected against GPX4 protein degradation and subsequent lipid peroxidation (Zhu et al., 2017), and GSH-specific gammaglutamylcyclotransferase 1 (CHAC1) degradation of GSH enhanced ferroptosis through GCN2-eIF2 $\alpha$-ATF4-GPX4 pathway (Chen et al., 2017). Selenium (Se) is an essential micronutrient associated with a broad array of health-promoting effects. Recently, Se was confirmed as a necessary micronutrient in the function of GPX4. When Se in GPX4 was replaced by sulfur, GPX4 loses its ability to inhibit ferroptosis and caused death in a mouse model (Ingold et al., 2018). Remarkably, pharmacological Se supplementation effectively inhibits GPX4dependent ferroptotic death as well as cell death induced by excitotoxicity or endoplasmic reticulum (ER) stress, which is GPX4 independent (Alim et al., 2019). Collectively, GPX4 synthesis and the function-related pathway are essential in ferroptosis regulation.

\section{The Iron Metabolism-Related Pathway for Ferroptosis Regulation}

Iron is a redox-active metal that can be engaged in free radical formation and propagation of lipid peroxidation. Therefore, the levels of iron can increase the sensitivity for ferroptosis (Hassannia et al., 2019). Iron is also necessary for mitochondrial function, synaptic plasticity, and cognitive function development. Excessive intracellular iron accelerates senescence by destroying DNA and blocking the genome repair system, and such a process was defined as the occurrence of ferritin aging (Sfera et al., 2018). When iron homeostasis in the body is out of balance, autophagy of ferritin (namely, ferritinophagy) mediated by nuclear receptor coactivator 4 (NCOA4) releases iron bounds to ferritin (Kruer, 2013; Dowdle et al., 2014; Mancias et al., 2014; Gao et al., 2016) or an abnormal increase in labile iron pools (LIP) through dysregulation of transferrin and transferrin receptors (iron from the extracellular environment) (Gao et al., 2016; Hou et al., 2016). Then through the Fenton reaction [Fenton's chemistry refers to a series of reactions between peroxides and divalent ferrous salts, producing oxygen-centered free radicals (Winterbourn, 1995)], producing hydroxyl and peroxy radicals, then extracts oxygen atoms from PUFA diallyl carbon and induces PUFAPLs peroxidation (Gaschler and Stockwell, 2017), and finally induced ferroptosis. Heme oxygenase-1 (HO-1/HMOX1) is a cytoprotective enzyme induced in response to cellular stress. $\mathrm{HO}$ 1 mainly catalyzes the degradation of heme to biliverdin, carbon monoxide (CO), and $\mathrm{Fe} 2^{+}$, and then increasing LIP to enhance ferroptosis (Adedoyin et al., 2018; Chang et al., 2018).

Mitochondria also make an important impact on regulating iron homeostasis. The NEET (gene symbol, 2 iron, 2 sulfur cluster binding protein. Ordered locus name: At5g51720) proteins mitoNEET \{encoded by CDGSH [gene sequence, the ironsulfur (2Fe-2S) binding motif; the conserved sequence $\mathrm{C}-\mathrm{X}$ C-X2-(S/T)-X3-P-X-C-D-G-(S/A/T)-H is a defining feature of this unique family] iron sulfur domain 1 (CISD1) $\}$ is an outer mitochondrial membrane protein essential for sensing and regulation of iron and ROS homeostasis (Yuan et al., 2016; 
Mittler et al., 2018). MitoNEET receives its clusters from the mitochondrion and transfers them to acceptor proteins and limits mitochondrial iron uptake from LIP and therefore suppresses ferroptosis (Yuan et al., 2016). MitoNEET and NAF-1 [encoded by CDGSH iron sulfur domain 2 (CISD2)] interact together by transferring the 2F2-2S cluster to maintain the levels of iron in the mitochondria (Karmi et al., 2017). Voltage-dependent anion channel 1 (VDAC1) is a crucial player in the cross-talk between the mitochondria and the cytosol, and it is regulated by mitoNEET; mitoNEET gates VDAC1 when mitoNEET is oxidized. Further study found that pharmacological inhibition of VDAC1 prevents mitoNEET-dependent mitochondrial iron accumulation in situ (Lipper et al., 2019).

\section{Some News Finding for Ferroptosis Regulation}

High-mobility group box 1 (HMGB1) is a nuclear protein that plays a fundamental role in the regulation of DNA-associated events such as DNA repair, transcription, and replication. A recent study found that HMGB1 is a novel regulator of ferroptosis via the Ras-c-Jun N-terminal kinase (JNK)/p38 pathway (Ye et al., 2019), and further research found that HMGB1 is a damage-associated molecular pattern (DAMP) molecule released by ferroptotic cells in an autophagy-dependent manner (Wen et al., 2019). Non-coding RNA has also been shown to be involved in regulating ferroptosis in recent years. MicroRNA-137 plays a novel and indispensable role in ferroptosis by inhibiting glutaminolysis (Luo et al., 2018), and at the same time, microRNA-9 was demonstrated regulating ferroptosis by targeting glutamic-oxaloacetic transaminase 1 (GOT1) (Zhang K. et al., 2018). Long non-coding RNA LINC00336 served as an endogenous sponge of microRNA-6852 (MIR6852) to regulate the expression of cystathionine- $\beta$-synthase (CBS), and MIR6852 directly binds to LINC0036 and serves as a negative upstream regulator of CBS-mediated ferroptosis inhibition (Wang et al., 2019c).

\section{Research Progress of Nuclear Factor E2 Related Factor 2 on Ferroptosis Regulation}

$\mathrm{Nrf2}$ is a well-known transcription factor that plays a key role in antioxidation. Downstream genes of $\mathrm{Nrf} 2$ include $\mathrm{NAD}(\mathrm{P}) \mathrm{H}$ quinone oxidoreductase 1, HO-1, solute carrier family 7 membrane 11 (SLC7A11/xCT), $\mathrm{NAD}(\mathrm{P}) \mathrm{H}$ quinone oxidoreductase 1 , thioredoxin 1, phase II detoxifying enzymes (e.g., GSH S-transferase, UDP-glucuronosyltransferase, GPX4, GSH reductase, and glutamate-cysteine ligase subunits; GCLc and GCLm), and several multidrug resistance-associated transporters (Furfaro et al., 2016; Tonelli et al., 2018). Thus, Nrf2 is considered to be an important regulatory factor for ferroptosis (Abdalkader et al., 2018). The activity of Nrf2 is rigorously regulated by Keap1. Keap1 not only passively isolates Nrf2 from the cytoplasm but also plays an active role in targeting Nrf2 for ubiquitination and proteasomal degradation (Zhang et al., 2004; Furukawa and Xiong, 2005). Under normoxic conditions, Nrf2 binds to Keap1 and continues to be inactivated by ubiquitination and degradation in the proteasome (Lu et al., 2017). Once the body is in oxidative stress, or if there are a large number of electrophiles or cytotoxic agents, Nrf2 is released from the Keap1 binding site and rapidly transferred to the nucleus, subsequently interacting with the antioxidant response element (ARE) in the promoter region of the target gene and then activates the transcriptional pathway to balance oxidative stress and maintain cellular redox homeostasis (Zhang, 2006). Ferroptosis-related genes that are transcriptionally regulated by $\mathrm{Nrf2}$ have been reported, these include genes for GSH regulation (synthesis, cysteine supply via SLC7A11, GSH reductase, GPX4), NADPH regeneration which is critical for GPX4 activity [glucose-6-phosphate dehydrogenase (G6PD), phosphogluconate dehydrogenase, malic enzyme], and iron regulation (including iron export and storage, heme synthesis, and catabolism) (Abdalkader et al., 2018; Kerins and Ooi, 2018). We found that Nrf2 can directly or indirectly regulate ferroptosis-related proteins through the STRING database website and Cytoscape 3.7.1 software analysis (Figure 2). In the protein-protein interaction (PPI) network, we obtained that Nrf2 regulates ferroptosis primarily by directly affecting the synthesis and function of GPX4 and the peroxisome proliferator-activated receptor gamma (PPAR $\gamma)$ pathway, and we hypothesize that the regulation of intracellular iron concentration by $\mathrm{Nrf} 2$ is mainly through the Nrf2-HO-1 axis. HO-1 is a stress-inducible protein with potential anti-inflammatory and antioxidant properties. HO- 1 can metabolize heme to biliverdin, iron, and CO (Kweider et al., 2013). Although many studies have confirmed that Nrf2HO-1 pathway can regulate intracellular iron concentration (LIP) (Chillappagari et al., 2014; Tomiotto-Pellissier et al., 2018; Cataneo et al., 2019; Selvakumar et al., 2019), there is still no direct evidence to prove our hypothesis that intracellular iron concentration is mainly regulated by the Nrf2-HO-1 pathway. Further research is needed to confirm this hypothesis.

Nrf2 regulates ferroptosis in many ways, and the relationship between Nrf2 and the key pathways for ferroptosis regulation has already attracted attention (Table 1). When cells are exposed to ferroptosis inducers, the SQSTM1/p62-Keap1-Nrf2-AKR1C (metal-binding protein MT-1G) pathway is activated, and then activating transcription of quinone oxidoreductase-1, HO- 1 , and ferritin heavy chain-1, reducing the sensitivity of ferroptosis in the end (Sun et al., 2016b). Nrf2 can directly or indirectly regulate GPX4 expression and function. The gene responsible for the proteins that encode GSH synthesis, including SLC7A11 (system Xc-), GCLC/GLCM and GSS, GPX4, etc., and oxidoreductases that use GSH and NADPH to reduce oxidative substrates, such as GSH-S-transferase p1 (GSTP1) and $\alpha 1$ (GSTA1), peroxidase 1 (PRDX1) and 6 (PRDX6), and thioredoxin reductase (TXNRD1) are all targets of Nrf2 (Hayes and Dinkova-Kostova, 2014). Nrf2 directly binds to ARE sequence of SLC7A11 subunit promoter and then promotes the expression of SLC7A11 (Carpi-Santos and Calaza, 2018). Nrf2 overexpression or Keap1 knockdown can increase SLC7A11 expression, while inhibition of Nrf2 expression or overexpression of Keap1 decreases SLC7A11 protein expression levels, thereby altering the sensitivity to ferroptosis (Fan et al., 2017; Shin et al., 2017). However, recent research has indicated that PUFAs promoted cystine uptake 


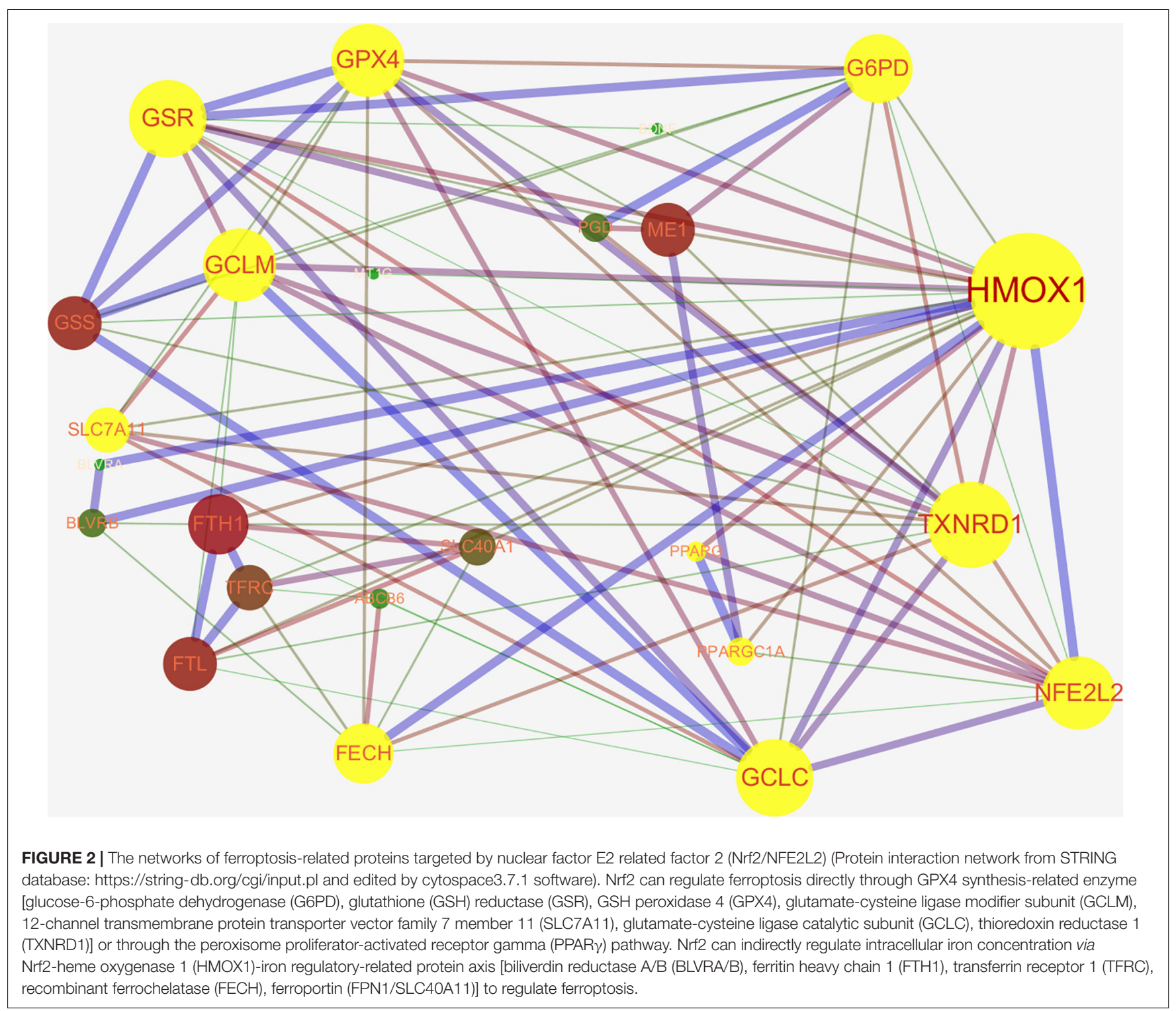

in placental cells by inducing xCT/SLC7A11 expression and Nrf2 did not contribute to upregulation of xCT/SLC7A11 by PUFAs (Ono et al., 2019). And an H2A deubiquitinase, tumor suppressor BAP1-mediated SLC7A11 inhibition, does not require Nrf2 and ATF4 transcription factors but represses SLC7A11 expression by reducing $\mathrm{H} 2 \mathrm{~A}$ ubiquitination ( $\mathrm{H} 2 \mathrm{Aub}$ ) on the SLC7A11 promoter (Zhang et al., 2019). When Keap1 has been inhibited, the activity of $\mathrm{Nrf} 2$ increases, resulting in upregulation of the ATP-binding cassette (ABC)-family transporter multidrug resistance protein (MRP1), which prevents GSH efflux from the cell and strongly inhibits ferroptosis (Cao et al., 2019). Therefore, we speculate that Nrf2 partially targets SLC7A11 to regulate GPX4 synthesis and function and thereby regulates ferroptosis.

Among the regulatory factors known to ferroptosis, the light and heavy chains (FTL/FTH1) of the key iron storage protein ferritin in the body and ferritin (SLC40A1) responsible for extracellular effluent cells are controlled by Nrf2 (Agyeman et al., 2012). A study recently found that ferroptosis inducers RSL3 and ML-162 induce ER stress via the PKR-like ER kinase (PERK)-ATF4-SESN2 pathway and subsequently induce p62 expression. p62 further inactivates Keap1, and Nrf2 was activated by p62-Keap1 interaction, and the ARE associated with iron and antioxidant systems was increased at the same time, resulting in LIP reduction (Shin et al., 2018). Exposure of astrocytes to $\mathrm{Fe}^{+}$resulted in increased Nrf2 time- and concentrationdependent expression, whereas knockdown of Nrf2 levels by siRNA resulted in greater toxicity of $\mathrm{Fe}^{+}{ }^{+}$-induced astrocytes (Cui et al., 2016). Targeting the Nrf2-HO-1 axis has been considered as a key pathway regulating cellular inflammation and oxidative stress levels (Chen-Roetling and Regan, 2017; Shin et al., 2019; Zhou et al., 2019). Heme oxygenase (HO/HMOX1) is a cytoprotective enzyme that operates as a key rate-limiting enzyme in the process of degradation of the iron-containing molecule, heme, yielding the following by-products: CO, iron, 
TABLE 1 | NRF2 target genes are involved in regulating ferroptsis.

\begin{tabular}{|c|c|c|c|c|}
\hline Gene & Protein Name & Function & Regulation of Ferroptosis & References \\
\hline \multicolumn{5}{|c|}{ Iron Homeostasis-Related } \\
\hline HMOX1 $(\mathrm{HO}-1)$ & Heme oxygenase 1 & $\begin{array}{l}\text { Metabolizes heme to biliverdin, iron } \\
\left(\mathrm{Fe}^{2+}\right) \text { and carbon monoxide }(\mathrm{CO})\end{array}$ & $\begin{array}{l}\text { Cellular iron availability, labile iron pools } \\
\text { (LIP) homeostasis }\end{array}$ & $\begin{array}{l}\text { Kweider et al., 2013; Chang } \\
\text { et al., 2018; Hassannia et al., } \\
\text { 2018; Hassannia et al., } 2019\end{array}$ \\
\hline TFRC & Transferrin receptor & Imports iron into cells & $\begin{array}{l}\text { Cellular transferrin-iron uptake, labile } \\
\text { iron pools (LIP) homeostasis }\end{array}$ & $\begin{array}{l}\text { Gao et al., 2016; Li et al., } \\
\text { 2017; Fillebeen et al., } 2019\end{array}$ \\
\hline $\mathrm{FTH} 1$ & Ferritin heavy chain 1 & $\begin{array}{l}\text { Stores iron in a soluble, non-toxic, } \\
\text { readily available form, subunit of ferritin }\end{array}$ & $\begin{array}{l}\text { Intracellular iron storage protein, labile } \\
\text { iron pools (LIP) homeostasis }\end{array}$ & $\begin{array}{l}\text { Andrews and Schmidt, 2007; } \\
\text { Bogdan et al., 2016; Sun } \\
\text { et al., 2016b; Dodson et al., } \\
2019\end{array}$ \\
\hline FTL & Ferritin light chain & & & \\
\hline SLC40A1 (FPN1) & Ferroportin & $\begin{array}{l}\text { External non-heme iron intake, exports } \\
\text { excess iron from cells }\end{array}$ & $\begin{array}{l}\text { Cellular iron exporter, labile iron pools } \\
\text { (LIP) homeostasis }\end{array}$ & $\begin{array}{l}\text { Theurl et al., 2016; Anderson } \\
\text { and Frazer, 2017; Brissot } \\
\text { et al., } 2018\end{array}$ \\
\hline BLVRA/B & Biliverdin reductase-A/B & $\begin{array}{l}\text { Converts biliverdin-IX-alpha into } \\
\text { bilirubin-IX-alpha }\end{array}$ & $\begin{array}{l}\text { Eliminates by-products of heme } \\
\text { metabolism, regulate heme-iron }\end{array}$ & $\begin{array}{l}\text { Sponholz et al., 2012; Zhang } \\
\text { Y. et al., } 2018\end{array}$ \\
\hline SLC48A1 (HRG1) & Heme responsive gene 1 & Heme transporter, recycles heme-iron & $\begin{array}{l}\text { Mobilizes heme to cytoplasm, recycles } \\
\text { heme-iron }\end{array}$ & $\begin{array}{l}\text { Rajagopal et al., 2008; } \\
\text { Campbell et al., 2013; White } \\
\text { et al., 2013; Zhang J. et al., } \\
2018\end{array}$ \\
\hline ABCB6 & $\begin{array}{l}\text { ATP-binding cassette } \\
\text { subfamily B member } 6\end{array}$ & $\begin{array}{l}\text { Exports and imports heme and its } \\
\text { precursors across the plasma } \\
\text { membrane, and outer mitochondrial } \\
\text { membrane, respectively }\end{array}$ & Regulate heme-iron homeostasis & $\begin{array}{l}\text { Helias et al., 2012; } \\
\text { Boswell-Casteel et al., } 2017\end{array}$ \\
\hline $\mathrm{FECH}$ & Ferrochelatase & $\begin{array}{l}\text { Catalyzes the insertion of } \mathrm{Fe} 2+\text { ion into } \\
\text { protoporphyrin IX }\end{array}$ & Heme biosynthesis & $\begin{array}{l}\text { Basavarajappa et al., 2017; } \\
\text { Mirmiran et al., } 2019\end{array}$ \\
\hline \multicolumn{5}{|c|}{ GPX4 Synthesis-Related } \\
\hline SLC7A11 & $\begin{array}{l}\text { Solute carrier family } 7 \\
\text { member } 11\end{array}$ & $\begin{array}{l}\text { Subunit of system Xc- to import cystine } \\
\text { in the cell }\end{array}$ & $\begin{array}{l}\text { Regulation of cysteine and glutamate } \\
\text { required for GPX4 synthesis }\end{array}$ & $\begin{array}{l}\text { Lang et al., 2019; Liu et al., } \\
\text { 2019; Wang et al., 2019d }\end{array}$ \\
\hline GCLM & $\begin{array}{l}\text { Glutamate-cysteine ligase } \\
\text { modifier subunit }\end{array}$ & $\begin{array}{l}\text { Enzyme involved in GSH synthesis } \\
\text { (modifier subunit) }\end{array}$ & Glutathione (GSH) synthesis & $\begin{array}{l}\text { Bea et al., 2003; Yang et al., } \\
\text { 2014; Lian et al., } 2018\end{array}$ \\
\hline GCLC & $\begin{array}{l}\text { Glutamate-cysteine ligase } \\
\text { catalytic subunit }\end{array}$ & $\begin{array}{l}\text { Enzyme involved in GSH synthesis } \\
\text { (catalytic subunit) }\end{array}$ & & \\
\hline GSS & Glutathione synthetase & $\begin{array}{l}\text { Catalyzes glutathione production from } \\
L-\gamma \text {-glutamyl-L-cysteine }\end{array}$ & Glutathione (GSH) synthesis & $\begin{array}{l}\text { Njålsson, 2005; Djulbegovic } \\
\text { and Uversky, 2019; Li F. } \\
\text { et al., } 2019\end{array}$ \\
\hline GSR & Glutathione reductase & $\begin{array}{l}\text { Catalyzes GSSG reduction to GSH by } \\
\text { using NADPH as a reducing cofactor }\end{array}$ & $\begin{array}{l}\text { Catalyzes glutathione disulfide (GSSG) } \\
\text { reduction to glutathione (GSH) }\end{array}$ & $\begin{array}{l}\text { Hoffmann et al., 2017; Kim } \\
\text { et al., } 2019\end{array}$ \\
\hline TXNRD1 & Thioredoxin reductase-1 & $\begin{array}{l}\text { Reduces thioredoxin-1 (Trx1) disulfide } \\
\text { and supply ATP }\end{array}$ & Fuels glutathione (GSH) synthesis & $\begin{array}{l}\text { Prigge et al., 2017; Ouyang } \\
\text { et al., } 2018\end{array}$ \\
\hline \multicolumn{5}{|c|}{ Lipid Peroxidation-Related } \\
\hline GPX4 & Glutathione peroxidase 4 & $\begin{array}{l}\text { Reduces membrane phospholipid } \\
\text { hydroperoxides }\end{array}$ & Reduces phospholipid hydroperoxide & $\begin{array}{l}\text { Yang et al., 2014; Doll et al., } \\
\text { 2019; Gao et al., } 2019\end{array}$ \\
\hline SCD1 & Stearoyl-CoA Desaturase 1 & Lipid synthesis & $\begin{array}{l}\text { Monounsaturated fatty acid synthesis, } \\
\text { decreases } \mathrm{CoQ}_{10}\end{array}$ & $\begin{array}{l}\text { Huang et al., 2010; Carbone } \\
\text { and Melino, 2019; Tesfay } \\
\text { et al., } 2019\end{array}$ \\
\hline SHP (NROB2) & Small heterodimer partner & Lipid metabolism & Unknown; lack of direct evidence & $\begin{array}{l}\text { Huang et al., 2010; Dodson } \\
\text { et al., } 2019\end{array}$ \\
\hline PPAR- $\gamma$ & $\begin{array}{l}\text { Peroxisome } \\
\text { proliferator-activated receptor } \\
\text { gamma }\end{array}$ & Lipid uptake & Unknown; lack of direct evidence & $\begin{array}{l}\text { Huang et al., 2010; } \\
\text { Abdalkader et al., } 2018\end{array}$ \\
\hline \multicolumn{5}{|l|}{ Others } \\
\hline MT1G & Metallothionein-1G & $\begin{array}{l}\text { Protection against heavy metals and } \\
\text { oxidative injury }\end{array}$ & $\begin{array}{l}\text { Through MT1G-Nrf2 } \\
\text { pathway/MT1G-P53-P21 pathway }\end{array}$ & $\begin{array}{l}\text { Sun et al., 2016a; Wang } \\
\text { et al., 2019e }\end{array}$ \\
\hline G6PD & $\begin{array}{l}\text { Glucose-6-phosphate } \\
\text { dehydrogenase }\end{array}$ & $\begin{array}{l}\text { Produces ribose and nicotinamide } \\
\text { adenine dinucleotide phosphate } \\
\text { (NADPH) via the pentose-phosphate } \\
\text { pathway (PPP). }\end{array}$ & NADPH regeneration & $\begin{array}{l}\text { Dodson et al., 2019; Yang } \\
\text { et al., } 2019\end{array}$ \\
\hline $\operatorname{miR}-7$ & MicroRNA-7 & $\begin{array}{l}\text { Negatively control gene expression by } \\
\text { binding to their target sequences in the } \\
\text { 3'-UTR of mRNAs }\end{array}$ & $\begin{array}{l}\text { miR-7-Keap1-Nrf2-HO-1/GCLM } \\
\text { pathway }\end{array}$ & Kabaria et al., 2015 \\
\hline
\end{tabular}

NRF2, nuclear factor E2 related factor 2. 
and biliverdin (Rochette et al., 2018; Maamoun et al., 2019). In murine models of doxorubicin (DOX) and ischemia/reperfusion (I/R)-induced cardiomyopathy, administering DOX to mice induced cardiomyopathy with a rapid, systemic accumulation of non-heme iron via heme degradation by Nrf2-mediated upregulation of HO-1, which effect was abolished in Nrf2deficient mice (Fang et al., 2019). In acute iron exposure, $\mathrm{Nrf} 2$ may protect from iron-induced injury, whereas long-term iron exposure resulted in iron accumulation, cytosolic ROS formation, and increased HO-1 (HMOX-1) mRNA expression, and this was accompanied by nuclear translocation of Nrf2 and induction of its target protein NQO1 (van Raaij et al., 2018). Accordingly, these evidences prove the hypothesized that Nrf2 can regulate intracellular iron metabolism through the Nrf2-HO1 axis pathway to regulate ferroptosis.

During the process of ferroptosis, the mitochondrial crest was decreased or disappeared, the membrane potential was changed, and the mitochondrial outer membrane was ruptured, and this led to mitochondrial function disruption. Nrf2 is required for acute exercise-induced increases in mitochondrial biogenesis genes in skeletal muscle, energy consumption, mitochondrial volume, antioxidant activity were reduced after exercise training in mice with impaired Nrf2 expression, in muscle cells of mice, ROS- and NO-regulated mitochondrial biogenesis through the Nrf2/Nrf1-dependent pathway (Merry and Ristow, 2016). PPAR $\gamma$ coactivator-1 $\alpha$ (PGC-1 $\alpha$ ) acts as a key factor and connects several regulatory cascades involved in the control of mitochondrial metabolism. PGC-1 $\alpha$ knockout dysregulates the Nrf2-dependent mitochondrial biogenesis through the PGC- $1 \alpha / \mathrm{p} 38 / \mathrm{GSK} 3 \beta / \mathrm{Nrf} 2$ cascade (Navarro et al., 2017; Gureev et al., 2019). In the course of research whether and how naringenin (NGN) would be able to prevent the mitochondria-related bioenergetics and redox dysfunctions induced by methylglyoxal (MG) in the human neuroblastoma SH-SY5Y cells, researchers found that NGN caused mitochondrial protection by an Nrf2/GSH-dependent manner (de Oliveira et al., 2019). Protein kinase mammalian sterile 20-like kinase 1 (MST1) modulates inflammation via multiple effects; Nrf2 expression was increased after deletion of MST1, whereas silencing of Nrf2 abolished the protective effects of Mst1 deletion on nasal epithelium survival and mitochondrial homeostasis (Song et al., 2019). Therefore, Nrf2 plays a key role in mitochondrial biogenesis and function and further regulates the process of ferroptosis.

\section{Research Progress on Ferroptosis and Neurodegenerative Diseases}

Iron is the most abundant transition metal in the brain. In the CNS, iron can participate in critical functions including mitochondrial energy transduction, enzyme catalysis, mitochondrial function, myelination, synaptic plasticity (Devos et al., 2014), and neurotransmitter synthesis and decomposition (Lane et al., 2018). The blood-brain barrier (BBB) ingests iron through transferrin on brain capillary endothelial cells, and then transports it into the cerebral cytoplasm through astrocytes or through divalent cation-binding protein (DMT1) and maintains iron an approximately saturated steady state in the brain (Belaidi and Bush, 2016), thereby maintaining the normal physiological function of the nervous system. After the formal concept of ferroptosis publishing, the researchers began to believe that ferroptosis is the main driver of neuronal death in diseases such as PD, AD, and HD (Guiney et al., 2017; Morris et al., 2018; Mi et al., 2019). In animal models of aging and neurodegenerative diseases and human anatomy studies, iron levels in the brain were found to rise to varying degrees, and it was concluded that this increase may lead to age-dependent ferroptosis (Belaidi and Bush, 2016; Buijs et al., 2017). And studies also found that chronic exposure to iron for mice caused a disorder of membrane-transport protein function and intracellular iron homeostasis and resulted in a significant increase in ROS and free radical MDA, ultimately leading to neuron and glial cell dysfunction and even neuron loss (Li L. B. et al., 2019). In summary, iron content in nerve cells may play a key role in the association of neurodegenerative diseases with ferroptosis.

\section{Ferroptosis in Alzheimer's Disease}

$\mathrm{AD}$ is the most common neurodegenerative disease characterized by neurofibrillary tangles (NFTs) composed of Tau protein. Levels of iron and ferritin (iron storage protein) in brain tissue are associated with the amount of amyloid deposition (Bulk et al., 2018; Gong et al., 2019). Deletion of hippocampal neurons and astrocyte proliferation by inducing GPX4 deletion in adult mice, this change links AD to ferroptosis (Yoo et al., 2012). $\alpha$-Lipoic acid (LA), a naturally occurring enzyme cofactor with antioxidant and iron chelator, studies have found that LA can stabilize cognitive function in $\mathrm{AD}$ patients by blocking tau-induced iron overload, lipid peroxidation, and ferroptosisrelated inflammation (Zhang Y. H. et al., 2018). Recent studies have found that trihydroxychalcone is a treatment for $\mathrm{AD}$ by simultaneously inhibiting $A \beta_{1-42}$ aggregation and ferroptosis (Cong et al., 2019), and ferroptosis-specific inhibitor Fer-1 can inhibit the accumulation of ROS/RNS and reduce the accumulation of $\alpha$-synuclein under rotenone-induced oxidative stress, then protect neuroblastoma cells SH-SY5Y (Kabiraj et al., 2015). Double-stranded RNA-dependent protein kinase (PKR) is a component of a signal transduction pathway that mediates a variety of stress signals, including oxidative stress and ER stress, and is thought to be involved in neurodegenerative diseases. The researchers found that inhibition of PKR in HT22 cells can effectively inhibit endogenous oxidative stress-induced ferroptosis and protect HT22 hippocampal neurons (Hirata et al., 2019). According to existing research, there is abundant evidence to support a causative interplay between the concerted loss of iron homeostasis and amyloid plaque formation (Peters et al., 2015). The researchers found that iron-induced amyloid precursor protein (APP) processing, neuronal signaling, and cognitive behavioral damage while using cultured primary cortical neurons and APP/PS1 AD model mice to study the mechanism of $\mathrm{AD}$-related mechanisms of iron-sulfate exposure in vitro and in vivo (Becerril-Ortega et al., 2014). Iron overload increases the production of KPI-APP and amyloid $\beta$ by amyloid (BecerrilOrtega et al., 2014), which promoted the AD process. Therefore, in the process of $\mathrm{AD}$ disease, ferroptosis may play an important role, and it is worth further exploration. 


\section{Ferroptosis in Parkinson's Disease}

The neuropathological features of PD are the loss of catecholamine neurons in vulnerable brain regions, including substantia nigra (SN) pars compacta (SNc) and blue spot, and the $\mathrm{PD}$ is biochemically characterized by mitochondrial dysfunction, accumulation of iron, diminished copper content, and depleted GSH levels in these regions (Liddell and White, 2018). It was beneficial for PD when using ferroptosis inhibitor-iron chelator deferiprone for PD treatment in a randomized controlled trial (Devos et al., 2014), and deferiprone could protect SN neurons and prevent PD progression in this trial. Studies have also found that ferroptosis was triggered by activation of protein kinase alpha (PKC-alpha), which then activated ERK-protein kinase [ERK-activating kinase (MEK)] in a Ras-independent manner, and then facilitated the process of PD diseases (Do Van et al., 2016). Excessive labile iron in the SNc has become a pathognomonic hallmark of $\mathrm{PD}$ and leads to increased production of noxious ROS, and it is common in PD-related diseases (Moreau et al., 2018). The researchers performed quantitative susceptibility mapping (QSM) iron deposition in the SN of 44 PD patients and 31 age- and sex-matched healthy controls and PD patients were found to exhibit significantly higher magnetic sensitivity values, especially in patients at advanced stage severity, confirming that iron accumulation in SN is consistent with PD progression (An et al., 2018). So it is concluded that ferroptosis may play an important role in the progression of $\mathrm{PD}$ disease, and that $\mathrm{PD}$ has been undergoing clinical evaluation through a conservative chelation mode based on drug-mediated iron redistribution (Moreau et al., 2018), and it might be a chance to cure PD in the future. Mitochondrial damage occurs in the early stages of PD and a large body of evidence indicates that the activity of mitochondrial complex I was impaired in tissues after the death of $\mathrm{PD}$, and another typical feature of PD was that GSH is selectively depleted from the (Liddell and White, 2018). These characteristics are the most typical characteristics of ferroptosis, suggesting that ferroptosis may play a key role in the progression of PD disease.

\section{Ferroptosis in Other Neurodegenerative Diseases}

Studies have found that the 4-hydroxy-2-non-enal (4-HNE) adduct (a lipid peroxidation marker) in the caudate and putamen of $\mathrm{HD}$ brain and the striatum of $\mathrm{HD}$ mice was increased (Lee et al., 2011). And in the study of the damage of dopaminergic neurons by paraquat and mancozeb, it was found that NADPH oxidase activation caused lipid peroxidation, which led to ferroptosis in SH-SY5Y cells (Hou et al., 2019). Besides, the rupture of the vessel wall in hemorrhagic stroke results in the accumulation and dissolution of iron-rich erythrocytes in the brain parenchyma and subsequent excessive presence of hemoglobin and heme iron in the extracellular environment, resulting in iron-induced lipid peroxidation and ferroptosis (DeGregorio-Rocasolano et al., 2019). Particularly, recent research found that neurons respond to ferroptotic stimuli by induction of selenoproteins, including antioxidant GSH peroxidase 4 (GPX4). A single dose of Se delivered into the brain drives antioxidant GPX4 expression, protects neurons, and improves behavior in a hemorrhagic stroke model (Alim et al., 2019). Friedreich ataxia (FRDA) is a progressive neurological and cardiac degenerative disease caused by repeated amplification of GAA in the first intron of two alleles of the FXN gene. In FRDA, the expression of the encoded protein frataxin was decreased, leading to obstruction of mitochondrial matrix iron-sulfur cluster biosynthesis, mitochondrial dysfunction, and mitochondrial iron accumulation, and finally result in increased oxidative stress. Studies have found that cells treated with ferric ammonium citrate (FAC) and L-buthionine-sulfoximine (BSO) consistently show reduced GSH-dependent peroxidase activity and increased lipid peroxidation in FRDA disease model (Cotticelli et al., 2019). When comparing the erastin in the induction of ferroptosis in neurons and HT1080 fibrosarcoma cells, it was found that selective protection of neurons by class I histone deacetylase (HDAC) inhibitors and accelerated cancer cell ferroptosis (Zille et al., 2019). Through literature review, it is speculated that in animal models of neurodegenerative diseases, depletion of long-term nuclear receptor-assisted activator (NCOA4) in the brain can worsen the neurodegenerative disease phenotype due to the further inappropriate accumulation of free iron and resulted in oxidative stress (Quiles Del Rey and Mancias, 2019), and then induced ferroptosis in nerve cells. Neurodegenerative iron accumulation (NBIA) is considered to be a neurodegenerative disease. In addition to iron accumulation, it also displays the corresponding pathological changes of tau protein in $\mathrm{AD}$ or synaptic nucleoprotein in PD during the NBIA process (Kruer, 2013). In conclusion,we can refer that ferroptosis may be a pathological form of neurodegenerative disease.

\section{EVIDENCE FOR NUCLEAR FACTOR E2 RELATED FACTOR 2 REGULATING FERROPTOSIS IN NEURODEGENERATIVE DISEASES}

Melatonin (MLT) is a chronobiotic hormone that tightly regulates the circadian rhythms setting a biological clock in vertebrates. Meanwhile, MLT is also known to regulate fundamental cellular functions by exhibiting antioxidant, antiaging, antivenom, oncostatic, cytoprotective, and immunomodulatory activities (Hardeland, 2018). Studies found that melatonin administration can reverse nervous system harmful effects of $\mathrm{Mn}$ through inhibition of Keap1 and consequently, activation of the Nrf2/ARE signaling pathway (Deng et al., 2015; Ahmadi and Ashrafizadeh, 2019). Recently, research has confirmed that hemin-induced ferroptosis in platelets is mediated through ROS-driven proteasome activity and inflammasome activation, which were mitigated by MLT (NaveenKumar et al., 2019). Moreover, when studying the role of cortical astrocytes in a mouse model of cerebral hemorrhage [intracerebral hemorrhage (ICH)], researchers found that MLT activates astrocytes through $\mathrm{PKC} \alpha / \mathrm{Nrf2} / \mathrm{HO}-1$ signaling pathway to acquire resistance to the toxicity of hemin and resist from oxidative stress (Chen et al., 2019). Brain-derived neurotrophic factor (BDNF) has been 
certified playing a key role in the regulation of redox-sensitive transcription factor Nrf 2 in astrocytes and metabolic cooperation between astrocytes and neurons. Stimulation by BDNF generates the signaling molecule ceramide, which activates PKC $\zeta$, leading to induction of the $\mathrm{CK} 2-\mathrm{Nrf} 2$ signaling axis, thereby protecting dopaminergic neurons from ferroptosis (Ishii et al., 2019). Although we hypothesize the regulation of Nrf 2 in the ferroptosis process of neurodegenerative diseases, it is unclear whether the neuroprotective effect in neurodegenerative disease model is through targeting Nrf2 to suppress ferroptosis regulation.

\section{CONCLUSION AND FUTURE PROSPECTS}

As a new and unique form of programed cell death, ferroptosis has aroused great interest in scientists since it was termed in 2012. Ferroptosis is initiated by severe lipid peroxidation relying on ROS generation and intracellular iron overload, but many of its physiological effects are yet to be defined. Oxidative stress can lead to the loss of neurons in various diseases and aging processes. Two key pathways to the maintenance of redox homeostasis in the body are GSH and thioredoxin antioxidant pathways. Not only is GSH regulated by Nrf2, the thioredoxin-based antioxidant system (TXN1, TXNRD1) is also regulated by Nrf2, indicating that Nrf2 regulates the redox state of proteins (Reisman et al., 2009). With the burgeoning in ferroptosis research, numerous proteins have been shown to be involved in the regulation of ferroptosis and can roughly classify them into four categories: GPX4 synthesis and function-related, iron metabolism-related, lipid peroxidation-related, transcription factors and others. Of particular importance is the fact that the GPX4 synthesis and function, intracellular iron homeostasis, and lipid peroxidation clearing can all be mediated by Nrf 2 target genes. We further verified the regulatory effect of $\mathrm{Nrf} 2$ on ferroptosis-related pathways through PPI network analysis and combined the existing evidence to propose the hypothesis that intracellular iron

\section{REFERENCES}

Abdalkader, M., Lampinen, R., Kanninen, K. M., Malm, T. M., and Liddell, J. R. (2018). Targeting Nrf2 to suppress Ferroptosis and mitochondrial dysfunction in neurodegeneration. Front. Neurosci. 12:466. doi: 10.3389/fnins.2018.00466

Adedoyin, O., Boddu, R., Traylor, A., Lever, J. M., Bolisetty, S., George, J. F., et al. (2018). Heme oxygenase-1 mitigates Ferroptosis in renal proximal tubule cells. Am. J. Physiol. Renal Physiol. 314, F702-F714. doi: 10.1152/ajprenal.00044.2017

Agmon, E., Solon, J., Bassereau, P., and Stockwell, B. R. (2018). Modeling the effects of lipid peroxidation during Ferroptosis on membrane properties. Sci. Rep. 8:5155. doi: 10.1038/s41598-018-23408-0

Agyeman, A. S., Chaerkady, R., Shaw, P. G., Davidson, N. E., Visvanathan, K., Pandey, A., et al. (2012). Transcriptomic and proteomic profiling of KEAP1 disrupted and sulforaphane-treated human breast epithelial cells reveals common expression profiles. Breast Cancer Res. Treat. 132, 175-187. doi: 10. 1007/s10549-011-1536-9

Ahmadi, Z., and Ashrafizadeh, M. (2019). Melatonin as a potential modulator of Nrf2. Fundam. Clin Pharmacol. 34, 11-19. doi: 10.1111/fcp.12498

Alim, I., Caulfield, J. T., Chen, Y., Swarup, V., Geschwind, D. H., Ivanova, E., et al. (2019). Selenium drives a transcriptional adaptive program to block Ferroptosis and treat stroke. Cell 177, 1262-1279.e25. doi: 10.1016/j.cell.2019.03.032 concentration is mainly regulated by the Nrf2-HO- 1 pathway, although more direct evidence is needed to verify the hypothesis.

Nrf2 has also become a consensus in the regulation of neurodegenerative diseases. There is already ample evidence that ferroptosis does occur during neurodegenerative diseases, and the treatment of neurodegenerative diseases through targeting ferroptosis regulators has proven to be reliable. Therefore, targeting the antioxidant transcription factor Nrf2 to suppress ferroptosis is an attractive new option for neurodegenerative control. Even though targeting Nrf2 has been demonstrated to exert anti-ferroptosis effects in the context of cancer cells, there is still insufficient evidence in the field of neurodegenerative disease therapy, and the specific markers, genetic regulation, and other studies have not been clear. Therefore, this paper reviews the new finding in ferroptosis regulation, the relationship between Nrf2 and ferroptosis, and the research progress of ferroptosis in neurodegenerative diseases. In summary, we propose that the regulation of neuronal and neuronal ferroptosis by targeting Nrf2 is expected to become a new direction for the prevention and treatment of neurodegenerative diseases. And it is of great significance for the study of human neurological diseases and aging, especially in neurodegenerative diseases such as $\mathrm{PD}, \mathrm{AD}$, and $\mathrm{HD}$.

\section{AUTHOR CONTRIBUTIONS}

XS and DL wrote the manuscript through a large number of literature research. DL guided the writing and reformed the manuscript. All authors contributed to the literature review, discussion, and writing of the manuscript.

\section{FUNDING}

This research was supported by the National Natural Science Foundation of China (Grant Numbers 81673227 and 81172712).
An, H., Zeng, X., Niu, T., Li, G., Yang, J., Zheng, L., et al. (2018). Quantifying iron deposition within the substantia nigra of Parkinson's disease by quantitative susceptibility mapping. J. Neurol. Sci. 386, 46-52. doi: 10.1016/j.jns.2018.01.008

Anderson, G. J., and Frazer, D. M. (2017). Current understanding of iron homeostasis. Am. J. Clin. Nutr. 106, 1559S-1566S. doi: 10.3945/ajcn.117. 155804

Andrews, N. C., and Schmidt, P. J. (2007). Iron homeostasis. Annu. Rev. Physiol. 69, 69-85.

Angeli, J. P. F., Shah, R., Pratt, D. A., and Conrad, M. (2017). Ferroptosis inhibition: mechanisms and opportunities. Trends Pharmacol. Sci. 38, 489-498. doi: 10. 1016/j.tips.2017.02.005

Anthonymuthu, T. S., Kenny, E. M., Shrivastava, I., Tyurina, Y. Y., Hier, Z. E., Ting, H. C., et al. (2018). Empowerment of 15-lipoxygenase catalytic competence in selective oxidation of membrane ETE-PE to ferroptotic death signals, HpETE-PE. J. Am. Chem. Soc. 140, 17835-17839. doi: 10.1021/jacs.8b0 9913

Basavarajappa, H. D., Sulaiman, R. S., Qi, X., Shetty, T., Sheik Pran Babu, S., et al. (2017). Ferrochelatase is a therapeutic target for ocular neovascularization. EMBO Mol. Med. 9, 786-801. doi: 10.15252/emmm.201606561

Bea, F., Hudson, F. N., Chait, A., Kavanagh, T. J., and Rosenfeld, M. E. (2003). Induction of glutathione synthesis in macrophages by oxidized low-density 
lipoproteins is mediated by consensus antioxidant response elements. Circ. Res. 92, 386-393. doi: 10.1161/01.res.0000059561.65545.16

Becerril-Ortega, J., Bordji, K., Freret, T., Rush, T., and Buisson, A. (2014). Iron overload accelerates neuronal amyloid-beta production and cognitive impairment in transgenic mice model of Alzheimer's disease. Neurobiol. Aging 35, 2288-2301. doi: 10.1016/j.neurobiolaging.2014.04.019

Belaidi, A. A., and Bush, A. I. (2016). Iron neurochemistry in Alzheimer's disease and Parkinson's disease: targets for therapeutics. J. Neurochem. 139(Suppl. 1), 179-197. doi: 10.1111/jnc. 13425

Bogdan, A. R., Miyazawa, M., Hashimoto, K., and Tsuji, Y. (2016). Regulators of iron homeostasis: new players in metabolism. Cell Death Dis. Trends Biochem. Sci. 41, 274-286. doi: 10.1016/j.tibs.2015.11.012

Boswell-Casteel, R. C., Fukuda, Y., and Schuetz, J. D. (2017). ABCB6, an ABC transporter impacting drug response and disease. AAPS J. 20:8. doi: 10.1208/ s12248-017-0165-6

Brissot, P., Pietrangelo, A., Adams, P. C., de Graaff, B., McLaren, C. E., and Loréal, O. (2018). Haemochromatosis. Nat. Rev. Dis. Primers. 4:18016. doi: 10.1038/ nrdp.2018.16

Buijs, M., Doan, N. T., van Rooden, S., Versluis, M. J., van Lew, B, Milles, J., et al. (2017). In vivo assessment of iron content of the cerebral cortex in healthy aging using 7-Tesla T2*-weighted phase imaging. Neurobiol. Aging 53, 20-26. doi: 10.1016/j.neurobiolaging.2016.09.005

Bulk, M., Kenkhuis, B., van der Graaf, L. M., Goeman, J. J., Natté, R., and van der Weerd, L. (2018). Postmortem T2*- weighted MRI imaging of cortical iron reflects severity of Alzheimer's disease. J. Alzheimers Dis. 65, 1125-1137. doi: $10.3233 /$ jad- 180317

Campbell, M. R., Karaca, M., Adamski, K. N., Chorley, B. N., Wang, X., and Bell, D. A. (2013). Novel hematopoietic target genes in the NRF2-mediated transcriptional pathway. Oxid. Med. Cell. Long. 2013:120305. doi: 10.1155/2013/ 120305

Cao, J. Y., Poddar, A., Magtanong, L., Lumb, J. H., Mileur, T. R., Reid, M. A., et al. (2019). A genome-wide haploid genetic screen identifies regulators of glutathione abundance and Ferroptosis sensitivity. Cell Rep. 26, 1544-1556.e8. doi: 10.1016/j.celrep.2019.01.043

Carbone, M., and Melino, G. (2019). Stearoyl CoA desaturase regulates Ferroptosis in ovarian cancer offering new therapeutic perspectives. Cancer Res. 79, 51495150. doi: 10.1158/0008-5472.CAN-19-2453

Carpi-Santos, R., and Calaza, K. C. (2018). Alterations in system xc(-) expression in the retina of Type 1 diabetic rats and the role of Nrf2. Mol. Neurobiol. 55, 7941-7948. doi: 10.1007/s12035-018-0961-8

Cataneo, A. H. D., Tomiotto-Pellissier, F., Miranda-Sapla, M. M., Assolini, J. P., Panis, C., Kian, D., et al. (2019). Quercetin promotes antipromastigote effect by increasing the ROS production and anti-amastigote by upregulating Nrf2/HO1 expression, affecting iron availability. Biomed. Pharmacother. 113:108745. doi: 10.1016/j.biopha.2019.108745

Chang, L. C., Chiang, S. K., Chen, S. E., Yu, Y. L., Chou, R. H., and Chang, W. C. (2018). Heme oxygenase-1 mediates BAY 11-7085 induced Ferroptosis. Cancer Lett. 416, 124-137. doi: 10.1016/j.canlet.2017.12.025

Chen, M. S., Wang, S. F., Hsu, C. Y., Yin, P. H., Yeh, T. S., Lee, H. C., et al. (2017). CHAC1 degradation of glutathione enhances cystine-starvationinduced necroptosis and Ferroptosis in human triple negative breast cancer cells via the GCN2-eIF2alpha-ATF4 pathway. Oncotarget 8, 114588-114602. doi: 10.18632/oncotarget.23055

Chen, X., Xi, Z., Liang, H., Sun, Y., Zhong, Z., Wang, B., et al. (2019). Melatonin prevents mice cortical astrocytes from hemin-induced toxicity through activating PKCalpha/Nrf2/HO-1 signaling in vitro. Front. Neurosci. 13:760. doi: $10.3389 /$ fnins.2019.00760

Chen-Roetling, J., and Regan, R. F. (2017). Targeting the Nrf2-heme oxygenase1 axis after intracerebral hemorrhage. Curr. Pharm. Des. 23, 2226-2237. doi: $10.2174 / 1381612822666161027150616$

Chillappagari, S., Venkatesan, S., Garapati, V., Mahavadi, P., Munder, A., Seubert, A., et al. (2014). Impaired TLR4 and HIF expression in cystic fibrosis bronchial epithelial cells downregulates hemeoxygenase- 1 and alters iron homeostasis in vitro. Am. J. Physiol. Lung. Cell Mol. Physiol. 307, L791-L799. doi: 10.1152/ ajplung.00167.2014

Chu, B., Kon, N., Chen, D., Li, T., Liu, T., Jiang, L., et al. (2019). ALOX12 is required for $\mathrm{p} 53$-mediated tumour suppression through a distinct Ferroptosis pathway. Nat. Cell Biol. 21, 579-591. doi: 10.1038/s41556-0190305-6
Cole, S. P. (2014). Multidrug resistance protein 1 (MRP1, ABCC1), a "multitasking" ATP-binding cassette (ABC) transporter. J. Biol. Chem. 289, 30880-30888. doi: 10.1074/jbc.R114.609248

Cong, L., Dong, X., Wang, Y., Deng, Y., Li, B., and Dai, R. (2019). On the role of synthesized hydroxylated chalcones as dual functional amyloid-beta aggregation and Ferroptosis inhibitors for potential treatment of Alzheimer's disease. Eur. J. Med. Chem. 166, 11-21. doi: 10.1016/j.ejmech.2019.01.039

Cotticelli, M. G., Xia, S., Lin, D., Lee, T., Terrab, L., Wipf, P., et al. (2019). Ferroptosis as a novel therapeutic target for Friedreich's Ataxia. J. Pharmacol. Exp. Ther. 369, 47-54. doi: 10.1124/jpet.118.252759

Cui, Z., Zhong, Z., Yang, Y., Wang, B., Sun, Y., Sun, Q., et al. (2016). Ferrous iron induces Nrf2 expression in mouse brain astrocytes to prevent neurotoxicity. J. Biochem. Mol. Toxicol. 30, 396-403. doi: 10.1002/jbt.21803

Daher, B., Parks, S. K., Durivault, J., Cormerais, Y., Baidarjad, H., Tambutte, E., et al. (2019). Genetic ablation of the cystine transporter XCT in PDAC cells inhibits mTORC1, growth, survival, and tumor formation via nutrient and oxidative stresses. Cancer Res. 79, 3877-3890. doi: 10.1158/0008-5472.can-183855

Dang, J., Brandenburg, L. O., Rosen, C., Fragoulis, A., Kipp, M., Pufe, T., et al. (2012). Nrf2 expression by neurons, astroglia, and microglia in the cerebral cortical penumbra of ischemic rats. J. Mol. Neurosci. 46, 578-584. doi: 10.1007/ s12031-011-9645-9

de Oliveira, M. R., Brasil, F. B., and Furstenau, C. R. (2018). Evaluation of the mitochondria-related redox and bioenergetics effects of gastrodin in SH-SY5Y cells exposed to hydrogen peroxide. J. Mol. Neurosci. 64, 242-251. doi: 10.1007/ s12031-018-1027-0

de Oliveira, M. R., Custodio De Souza, I. C., and Furstenau, C. R. (2019). Promotion of mitochondrial protection by naringenin in methylglyoxal-treated SH-SY5Y cells: involvement of the Nrf2/GSH axis. Chem. Biol. Interact. 310, 108728. doi: 10.1016/j.cbi.2019.108728

DeGregorio-Rocasolano, N., Marti-Sistac, O., and Gasull, T. (2019). Deciphering the iron side of stroke: neurodegeneration at the crossroads between iron dyshomeostasis, excitotoxicity, and Ferroptosis. Front. Neurosci. 13:85. doi: 10.3389/fnins.2019.00085

Deng, Y., Zhu, J., Mi, C., Xu, B., Jiao, C., Li, Y., et al. (2015). Melatonin antagonizes $\mathrm{Mn}$-induced oxidative injury through the activation of keap1-Nrf2ARE signaling pathway in the striatum of mice. Neurotox. Res. 27, 156-171. doi: 10.1007/s12640-014-9489-5

Deng, Z., Lim, J., Wang, Q., Purtell, K., Wu, S., Palomo, G. M., et al. (2019). ALS-FTLD-linked mutations of SQSTM1/p62 disrupt selective autophagy and NFE2L2/NRF2 anti-oxidative stress pathway. Autophagy 16, 917-931. doi: 10. 1080/15548627.2019.1644076

Devos, D., Moreau, C., Devedjian, J. C., Kluza, J., Petrault, M., Laloux, C., et al. (2014). Targeting chelatable iron as a therapeutic modality in Parkinson's disease. Antioxid. Redox. Signal. 21, 195-210. doi: 10.1089/ars.2013. 5593

Dixon, S. J., Lemberg, K. M., Lamprecht, M. R., Skouta, R., Zaitsev, E. M., Gleason, C. E., et al. (2012). Ferroptosis: an iron-dependent form of nonapoptotic cell death. Cell 149, 1060-1072. doi: 10.1016/j.cell.2012.03.042

Dixon, S. J., Winter, G. E., Musavi, L. S., Lee, E. D., Snijder, B., Rebsamen, M., et al. (2015). Human haploid cell genetics reveals roles for lipid metabolism genes in nonapoptotic cell death. ACS Chem. Biol. 10, 1604-1609. doi: 10.1021/ acschembio.5b00245

Djulbegovic, M. B., and Uversky, V. N. (2019). Ferroptosis - an iron- and disorderdependent programmed cell death. Int. J. Biol. Macromol. 135, 1052-1069. doi: 10.1016/j.ijbiomac.2019.05.221

Do Van, B, Gouel, F., Jonneaux, A., Timmerman, K., Gelé, P., Pétrault, M., et al. (2016). Ferroptosis, a newly characterized form of cell death in Parkinson's disease that is regulated by PKC. Neurobiol. Dis. 94, 169-178. doi: 10.1016/j. nbd.2016.05.011

Dodson, M., Castro-Portuguez, R., and Zhang, D. D. (2019). NRF2 plays a critical role in mitigating lipid peroxidation and Ferroptosis. Redox. Biol. 23:101107. doi: 10.1016/j.redox.2019.101107

Doll, S., Freitas, F. P., Shah, R., Aldrovandi, M., da Silva, M. C, Ingold, I., et al. (2019). FSP1 is a glutathione-independent Ferroptosis suppressor. Nature 575, 693-698. doi: 10.1038/s41586-019-1707-0

Doll, S., Proneth, B., Tyurina, Y. Y., Panzilius, E., Kobayashi, S., Ingold, I., et al. (2017). ACSL4 dictates Ferroptosis sensitivity by shaping cellular lipid composition. Nat. Chem. Biol. 13, 91-98. doi: 10.1038/nchembio.2239 
Dowdle, W. E., Nyfeler, B., Nagel, J., Elling, R. A., Liu, S., Triantafellow, E., et al. (2014). Selective VPS34 inhibitor blocks autophagy and uncovers a role for NCOA4 in ferritin degradation and iron homeostasis in vivo. Nat. Cell Biol. 16, 1069-1079. doi: 10.1038/ncb3053

Fan, Z., Wirth, A. K., Chen, D., Wruck, C. J., Rauh, M., Buchfelder, M., et al. (2017). Nrf2-Keap1 pathway promotes cell proliferation and diminishes Ferroptosis. Oncogenesis 6, 1-14. doi: 10.1038/oncsis.2017.65

Fang, X., Wang, H., Han, D., Xie, E., Yang, X., Wei, J., et al. (2019). Ferroptosis as a target for protection against cardiomyopathy. Proc. Natl. Acad. Sci. U.S.A. 116, 2672-2680. doi: 10.1073/pnas.1821022116

Feng, H., and Stockwell, B. R. (2018). Unsolved mysteries: how does lipid peroxidation cause Ferroptosis? PLoS Biol. 16:e2006203. doi: 10.1371/journal. pbio. 2006203

Fillebeen, C., Charlebois, E., Wagner, J., Katsarou, A., Mui, J., Vali, H., et al. (2019). Transferrin receptor 1 controls systemic iron homeostasis by finetuning hepcidin expression to hepatocellular iron load. Blood 133, 344-355. doi: 10.1182/blood-2018-05-850404

Forcina, G. C., and Dixon, S. J. (2019). GPX4 at the crossroads of lipid homeostasis and Ferroptosis. Proteomics 19:e1800311. doi: 10.1002/pmic.201800311

Friedmann Angeli, J. P, Schneider, M., Proneth, B., Tyurina, Y. Y., Tyurin, V. A., Hammond, V. J., et al. (2014). Inactivation of the Ferroptosis regulator Gpx4 triggers acute renal failure in mice. Nat. Cell Biol. 16, 1180-1191. doi: 10.1038/ ncb3064

Furfaro, A. L., Traverso, N., Domenicotti, C., Piras, S., Moretta, L., Marinari, U. M., et al. (2016). The Nrf2/HO-1 axis in cancer cell growth and chemoresistance. Oxid. Med. Cell. Longev. 2016:1958174. doi: 10.1155/2016/1958174

Furukawa, M., and Xiong, Y. (2005). BTB protein Keap1 targets antioxidant transcription factor Nrf2 for ubiquitination by the Cullin 3-Roc1 ligase. Mol. Cell. Biol. 25, 162-171. doi: 10.1128/mcb.25.1.162-171.2005

Galluzzi, L., Vitale, I., Aaronson, S. A., Abrams, J. M., Adam, D., Agostinis, P., et al. (2018). Molecular mechanisms of cell death: recommendations of the nomenclature committee on cell death 2018. Cell Death Differ. 25, 486-541. doi: 10.1038/s41418-017-0012-4

Gao, M., and Jiang, X. (2018). To eat or not to eat-the metabolic flavor of Ferroptosis. Curr. Opin. Cell. Biol. 51, 58-64. doi: 10.1016/j.ceb.2017.11.001

Gao, M., Monian, P., Pan, Q., Zhang, W., Xiang, J., and Jiang, X. (2016). Ferroptosis is an autophagic cell death process. Cell Res. 26, 1021-1032. doi: 10.1038/cr. 2016.95

Gao, M., Monian, P., Quadri, N., Ramasamy, R., and Jiang, X. (2015). Glutaminolysis and transferrin regulate Ferroptosis. Mol. Cell. 59, 298-308. doi: 10.1016/j.molcel.2015.06.011

Gao, M., Yi, J., Zhu, J., Minikes, A. M., Monian, P., Thompson, C. B., et al. (2019). Role of mitochondria in Ferroptosis. Mol. Cell. 73, 354-363.e3. doi: 10.1016/j. molcel.2018.10.042

Gaschler, M. M., and Stockwell, B. R. (2017). Lipid peroxidation in cell death. Biochem. Biophys. Res. Commun. 482, 419-425. doi: 10.1016/j.bbrc.2016.10.086

Gong, N. J., Dibb, R., Bulk, M., Van Der Weerd, L., and Liu, C. (2019). Imaging beta amyloid aggregation and iron accumulation in Alzheimer's disease using quantitative susceptibility mapping MRI. Neuroimage 191, 176-185. doi: 10. 1016/j.neuroimage.2019.02.019

Guiney, S. J., Adlard, P. A., Bush, A. I., Finkelstein, D. I., and Ayton, S. (2017). Ferroptosis and cell death mechanisms in Parkinson's disease. Neurochem. Int. 104, 34-48. doi: 10.1016/j.neuint.2017.01.004

Gureev, A. P., Shaforostova, E. A., and Popov, V. N. (2019). Regulation of mitochondrial biogenesis as a way for active longevity: interaction between the Nrf2 and PGC-1alpha signaling pathways. Front. Genet. 10:435. doi: 10.3389/ fgene.2019.00435

Hao, S., Liang, B., Huang, Q., Dong, S., Wu, Z., He, W., et al. (2018). Metabolic networks in Ferroptosis. Oncol. Lett. 15, 5405-5411. doi: 10.3892/ol.2018.8066

Hardeland, R. (2018). Melatonin and inflammation-story of a double-edged blade. J. Pineal. Res. 65:e12525. doi: 10.1111/jpi.12525

Hassannia, B., Vandenabeele, P., and Vanden Berghe, T. (2019). Targeting Ferroptosis to iron out cancer. Cancer Cell 35, 830-849. doi: 10.1016/j.ccell. 2019.04.002

Hassannia, B., Wiernicki, B., Ingold, I., Qu, F., Van Herck, S, Tyurina, Y. Y., et al. (2018). Nano-targeted induction of dual ferroptotic mechanisms eradicates high-risk neuroblastoma. J. Clin. Invest. 128, 3341-3355. doi: 10.1172/JCI99032
Hayes, J. D., and Dinkova-Kostova, A. T. (2014). The Nrf2 regulatory network provides an interface between redox and intermediary metabolism. Trends Biochem. Sci. 39, 199-218. doi: 10.1016/j.tibs.2014.02.002

Helias, V., Saison, C., Ballif, B. A., Peyrard, T., Takahashi, J., Takahashi, H., et al. (2012). ABCB6 is dispensable for erythropoiesis and specifies the new blood group system Langereis. Nat. Genet. 44, 170-173. doi: 10.1038/ng.1069

Hirata, Y., Iwasaki, T., Makimura, Y., Okajima, S., Oh-Hashi, K., and Takemori, H. (2019). Inhibition of double-stranded RNA-dependent protein kinase prevents oxytosis and Ferroptosis in mouse hippocampal HT22 cells. Toxicology 418, 1-10. doi: 10.1016/j.tox.2019.02.012

Hoffmann, C., Dietrich, M., Herrmann, A. K., Schacht, T., Albrecht, P., and Methner, A. (2017). Dimethyl fumarate induces glutathione recycling by upregulation of glutathione reductase. Oxid. Med. Cell. Long. 2017:6093903. doi: 10.1155/2017/6093903

Hou, L., Huang, R., Sun, F., Zhang, L., and Wang, Q. (2019). NADPH oxidase regulates paraquat and maneb-induced dopaminergic neurodegeneration through Ferroptosis. Toxicology 417, 64-73. doi: 10.1016/j.tox.2019.02.011

Hou, W., Xie, Y., Song, X., Sun, X., Lotze, M. T., Zeh, H. J. III, et al. (2016). Autophagy promotes Ferroptosis by degradation of ferritin. Autophagy 12, 1425-1428. doi: 10.1080/15548627.2016.1187366

Huang, J., Tabbi-Anneni, I., Gunda, V., and Wang, L. (2010). Transcription factor Nrf2 regulates SHP and lipogenic gene expression in hepatic lipid metabolism. Am. J. Physiol. Gastrointest. Liver Physiol. 299, G1211-G1221. doi: 10.1152/ ajpgi.00322.2010

Ingold, I., Berndt, C., Schmitt, S., Doll, S., Poschmann, G., Buday, K., et al. (2018). Selenium Utilization by GPX4 is required to prevent hydroperoxide-induced Ferroptosis. Cell 172, 409-422.e21. doi: 10.1016/j.cell.2017.11.048

Ishii, T., Warabi, E., and Mann, G. E. (2019). Circadian control of BDNF-mediated Nrf2 activation in astrocytes protects dopaminergic neurons from Ferroptosis. Free Radic. Biol. Med. 133, 169-178. doi: 10.1016/j.freeradbiomed.2018.0 9.002

Jang, M., Choi, J. H., Chang, Y., Lee, S. J., Nah, S. Y., and Cho, I. H. (2019). Gintonin, a ginseng-derived ingredient, as a novel therapeutic strategy for Huntington's disease: activation of the Nrf2 pathway through lysophosphatidic acid receptors. Brain Behav. Immun. 80, 146-162. doi: 10.1016/j.bbi.2019.0 3.001

Jiang, L., Kon, N., Li, T., Wang, S. J., Su, T., Hibshoosh, H., et al. (2015). Ferroptosis as a p53-mediated activity during tumour suppression. Nature 520, 57-62. doi: 10.1038/nature 14344

Kabaria, S., Choi, D. C., Chaudhuri, A. D., Jain, M. R., Li, H., and Junn, E. (2015). MicroRNA-7 activates Nrf2 pathway by targeting Keap1 expression. Free Radic. Biol. Med. 89, 548-556. doi: 10.1016/j.freeradbiomed.2015.09.010

Kabiraj, P., Valenzuela, C. A., Marin, J. E., Ramirez, D. A., Mendez, L., Hwang, M. S., et al. (2015). The neuroprotective role of ferrostatin-1 under rotenoneinduced oxidative stress in dopaminergic neuroblastoma cells. Protein J. 34, 349-358. doi: 10.1007/s10930-015-9629-7

Kagan, V. E., Mao, G., Qu, F., Angeli, J. P., Doll, S., Croix, C. S., et al. (2017). Oxidized arachidonic and adrenic PEs navigate cells to Ferroptosis. Nat. Chem. Biol. 13, 81-90. doi: 10.1038/nchembio.2238

Kang, R., Kroemer, G., and Tang, D. (2019). The tumor suppressor protein p53 and the Ferroptosis network. Free Radic. Biol. Med. 133, 162-168. doi: 10.1016/ j.freeradbiomed.2018.05.074

Karmi, O., Holt, S. H., Song, L., Tamir, S., Luo, Y., Bai, F., et al. (2017). Interactions between mitoNEET and NAF-1 in cells. PLoS One 12:e0175796. doi: 10.1371/ journal.pone.0175796

Kerins, M. J., and Ooi, A. (2018). The roles of NRF2 in modulating cellular iron homeostasis. Antioxid. Redox. Signal. 29, 1756-1773. doi: 10.1089/ars.2017. 7176

Kim, V. Y., Batty, A., Li, J., Kirk, S. G., Crowell, S. A., Jin, Y., et al. (2019). Glutathione reductase promotes fungal clearance and suppresses inflammation during systemic infection in mice. J. Immunol. (Baltimore, Md.) 203, 22392251. doi: 10.4049/jimmunol.1701686

Kruer, M. C. (2013). The neuropathology of neurodegeneration with brain iron accumulation. Int. Rev. Neurobiol. 110, 165-194. doi: 10.1016/b978-0-12410502-7.00009-0

Kweider, N., Wruck, C. J., and Rath, W. (2013). New insights into the pathogenesis of preeclampsia - the role of $\mathrm{Nrf} 2$ activators and their potential therapeutic 
impact. Geburtshilfe Frauenheilkd. 73, 1236-1240. doi: 10.1055/s-00331360133

Lane, D. J. R., Ayton, S., and Bush, A. I. (2018). Iron and Alzheimer's disease: an update on emerging mechanisms. J. Alzheimers Dis. 64, S379-S395. doi: 10.3233/jad-179944

Lang, X., Green, M. D., Wang, W., Yu, J., Choi, J. E., Jiang, L., et al. (2019). Radiotherapy and immunotherapy promote tumoral lipid oxidation and Ferroptosis via synergistic repression of SLC7A11. Cancer Discov. 9, 1673-1685. doi: 10.1158/2159-8290.CD-19-0338

Lee, J., Kosaras, B., Del Signore, S. J, Cormier, K., McKee, A., Ratan, R. R., et al. (2011). Modulation of lipid peroxidation and mitochondrial function improves neuropathology in Huntington's disease mice. Acta Neuropathol. 121, 487-498. doi: 10.1007/s00401-010-0788-5

Leu, J. I., Murphy, M. E., and George, D. L. (2019). Mechanistic basis for impaired Ferroptosis in cells expressing the African-centric S47 variant of p53. Proc. Natl. Acad. Sci. U.S.A. 116, 8390-8396. doi: 10.1073/pnas.1821277116

Li, F., Cui, L., Yu, D., Hao, H., Liu, Y., Zhao, X., et al. (2019). Exogenous glutathione improves intracellular glutathione synthesis via the $\gamma$-glutamyl cycle in bovine zygotes and cleavage embryos. J. Cell. Physiol. 234, 7384-7394. doi: 10.1002/jcp. 27497

Li, H., Choesang, T., Bao, W., Chen, H., Feola, M., Garcia-Santos, D., et al. (2017). Decreasing TfR1 expression reverses anemia and hepcidin suppression in $\beta$-thalassemic mice. Blood 129, 1514-1526. doi: 10.1182/blood-2016-09742387

Li, L. B., Chai, R., Zhang, S., Xu, S. F., Zhang, Y. H., Li, H. L., et al. (2019). Iron exposure and the cellular mechanisms linked to neuron degeneration in adult mice. Cells 8:198. doi: 10.3390/cells8020198

Li, Y., Feng, D., Wang, Z., Zhao, Y., Sun, R., Tian, D., et al. (2019). Ischemiainduced ACSL4 activation contributes to Ferroptosis-mediated tissue injury in intestinal ischemia/reperfusion. Cell Death Differ. 26, 2284-2299. doi: 10.1038/ s41418-019-0299-4

Lian, G., Gnanaprakasam, J. R., Wang, T., Wu, R., Chen, X., Liu, L., et al. (2018). Glutathione de novo synthesis but not recycling process coordinates with glutamine catabolism to control redox homeostasis and directs murine $\mathrm{T}$ cell differentiation. eLife 7:e36158. doi: 10.7554/eLife.36158

Liddell, J. R., and White, A. R. (2018). Nexus between mitochondrial function, iron, copper and glutathione in Parkinson's disease. Neurochem. Int. 117, 126-138. doi: 10.1016/j.neuint.2017.05.016

Lipper, C. H., Stofleth, J. T., Bai, F., Sohn, Y. S., Roy, S., Mittler, R., et al. (2019). Redox-dependent gating of VDAC by mitoNEET. Proc. Natl. Acad. Sci. U.S.A. 116, 19924-19929. doi: 10.1073/pnas.1908271116

Liu, T., Jiang, L., Tavana, O., and Gu, W. (2019). The deubiquitylase OTUB1 mediates Ferroptosis via stabilization of SLC7A11. Cancer Res. 79, 1913-1924. doi: 10.1158/0008-5472.can-18-3037

Louandre, C., Ezzoukhry, Z., Godin, C., Barbare, J. C., Mazière, J. C., Chauffert, B., et al. (2013). Iron-dependent cell death of hepatocellular carcinoma cells exposed to sorafenib. Int. J. Cancer 133, 1732-1742. doi: 10.1002/ijc.28159

Lu, K., Alcivar, A. L., Ma, J., Foo, T. K., Zywea, S., Mahdi, A., et al. (2017). NRF2 induction supporting breast cancer cell survival is enabled by oxidative stressinduced DPP3-KEAP1 interaction. Cancer Res. 77, 2881-2892. doi: 10.1158/ 0008-5472.can-16-2204

Luo, M., Wu, L., Zhang, K., Wang, H., Zhang, T., Gutierrez, L., et al. (2018). miR-137 regulates Ferroptosis by targeting glutamine transporter SLC1A5 in melanoma. Cell Death Differ. 25, 1457-1472. doi: 10.1038/s41418-017-0053-8

Maamoun, H., Benameur, T., Pintus, G., Munusamy, S., and Agouni, A. (2019). Crosstalk between oxidative stress and endoplasmic reticulum (ER) stress in endothelial dysfunction and aberrant angiogenesis associated with diabetes: a focus on the protective roles of heme oxygenase (HO)-1. Front. Physiol. 10:70. doi: 10.3389/fphys.2019.00070

Mancias, J. D., Wang, X., Gygi, S. P., Harper, J. W., and Kimmelman, A. C. (2014). Quantitative proteomics identifies NCOA4 as the cargo receptor mediating Ferritinophagy. Nature 509, 105-109. doi: 10.1038/nature13148

Merry, T. L., and Ristow, M. (2016). Nuclear factor erythroid-derived 2-like 2 (NFE2L2, Nrf2) mediates exercise-induced mitochondrial biogenesis and the anti-oxidant response in mice. J. Physiol. 594, 5195-5207. doi: 10.1113/ jp271957
Mi, Y., Gao, X., Xu, H., Cui, Y., Zhang, Y., and Gou, X. (2019). The emerging roles of Ferroptosis in Huntington's disease. Neuromol. Med. 21, 110-119. doi: 10.1007/s12017-018-8518-6

Mirmiran, A., Schmitt, C., Lefebvre, T., Manceau, H., Daher, R., Oustric, V., et al. (2019). Erythroid-progenitor-targeted gene therapy using bifunctional TFR1 ligand-peptides in human erythropoietic protoporphyria. Am. J. Hum. Genet. 104, 341-347. doi: 10.1016/j.ajhg.2018.12.021

Mittler, R., Darash-Yahana, M., Sohn, Y. S., Bai, F., Song, L., Cabantchik, I. Z., et al. (2018). neet proteins: a new link between iron metabolism, reactive oxygen species, and cancer. Antioxid. Redox. Signal. 30, 1083-1095. doi: 10.1089/ars. 2018.7502

Moreau, C., Duce, J. A., Rascol, O., Devedjian, J. C., Berg, D., Dexter, D., et al. (2018). Iron as a therapeutic target for Parkinson's disease. Mov. Disord. 33, 568-574. doi: $10.1002 / \mathrm{mds} .27275$

Morris, G., Berk, M., Carvalho, A. F., Maes, M., Walker, A. J., and Puri, B. K. (2018). Why should neuroscientists worry about iron? The emerging role of Ferroptosis in the pathophysiology of neuroprogressive diseases. Behav. Brain Res. 341, 154-175. doi: 10.1016/j.bbr.2017.12.036

Muhammad, T., Ikram, M., Ullah, R., Rehman, S. U., and Kim, M. O. (2019). Hesperetin, a citrus flavonoid, attenuates LPS-induced neuroinflammation, apoptosis and memory impairments by modulating TLR4/NF-kappaB signaling. Nutrients 11, 1-20. doi: 10.3390/nu11030648

Navarro, E., Gonzalez-Lafuente, L., Pérez-Liébana, I., Buendia, I., López-Bernardo, E., Sánchez-Ramos, C., et al. (2017). Heme-oxygenase I and PCG-1alpha regulate mitochondrial biogenesis via microglial activation of Alpha7 nicotinic acetylcholine receptors using PNU282987. Antioxid. Redox. Signal. 27, 93-105. doi: $10.1089 /$ ars.2016.6698

NaveenKumar, S. K., Hemshekhar, M., Kemparaju, K., and Girish, K. S. (2019). Hemin-induced platelet activation and Ferroptosis is mediated through ROSdriven proteasomal activity and inflammasome activation: protection by melatonin. Biochim. Biophys. Acta Mol. Basis Dis. 1865, 2303-2316. doi: 10. 1016/j.bbadis.2019.05.009

Njålsson, R. (2005). Glutathione synthetase deficiency. Cell. Mol. Life Sci. CMLS 62, 1938-1945. doi: 10.1007/s00018-005-5163-7

Ono, K., Furugen, A., Kurosawa, Y., Jinno, N., Narumi, K., Kobayashi, M., et al. (2019). Analysis of the effects of polyunsaturated fatty acids on transporter expressions using a PCR array: induction of xCT/SLC7A11 in human placental BeWo cells. Placenta 75, 34-41. doi: 10.1016/j.placenta.2018.11.010

Ou, Y., Wang, S. J., Li, D., Chu, B., and Gu, W. (2016). Activation of SAT1 engages polyamine metabolism with p53-mediated ferroptotic responses. Proc. Natl. Acad. Sci. U.S.A. 113, E6806-E6812. doi: 10.1073/pnas.1607152113

Ouyang, Y., Peng, Y., Li, J., Holmgren, A., and Lu, J. (2018). Modulation of thiol-dependent redox system by metal ions via thioredoxin and glutaredoxin systems. Metallomics 10, 218-228. doi: 10.1039/c7mt00327g

Pachón-Angona, I., Martin, H., Chhor, S., Oset-Gasque, M. J., Refouvelet, B., Marco-Contelles, J., et al. (2019). Synthesis of new ferulic/lipoic/comenic acidmelatonin hybrids as antioxidants and Nrf2 activators via Ugi reaction. Future Med. Chem. 11, 3097-3108. doi: 10.4155/fmc-2019-0191

Peters, D. G., Connor, J. R., and Meadowcroft, M. D. (2015). The relationship between iron dyshomeostasis and amyloidogenesis in Alzheimer's disease: two sides of the same coin. Neurobiol. Dis. 81, 49-65. doi: 10.1016/j.nbd.2015.0 8.007

Prigge, J. R., Coppo, L., Martin, S. S., Ogata, F., Miller, C. G., Bruschwein, M. D., et al. (2017). Hepatocyte hyperproliferation upon liver-specific co-disruption of thioredoxin-1, thioredoxin reductase-1, and glutathione reductase. Cell Rep. 19, 2771-2781. doi: 10.1016/j.celrep.2017.06.019

Quiles Del Rey, M., and Mancias, J. D. (2019). NCOA4-mediated ferritinophagy: a potential link to neurodegeneration. Front. Neurosci. 13:238. doi: 10.3389/fnins. 2019.00238

Rajagopal, A., Rao, A. U., Amigo, J., Tian, M., Upadhyay, S. K., Hall, C., et al. (2008). Haem homeostasis is regulated by the conserved and concerted functions of HRG-1 proteins. Nature 453, 1127-1131. doi: 10.1038/nature06934

Reisman, S. A., Yeager, R. L., Yamamoto, M., and Klaassen, C. D. (2009). Increased Nrf2 activation in livers from Keap1-knockdown mice increases expression of cytoprotective genes that detoxify electrophiles more than those that detoxify reactive oxygen species. Toxicol. Sci. 108, 35-47. doi: 10.1093/toxsci/kfn267 
Rochette, L., Zeller, M., Cottin, Y., and Vergely, C. (2018). Redox functions of heme oxygenase-1 and biliverdin reductase in diabetes. Trends Endocrinol. Metab. 29, 74-85. doi: 10.1016/j.tem.2017.11.005

Saint-Germain, E., Mignacca, L., Vernier, M., Bobbala, D., Ilangumaran, S., and Ferbeyre, G. (2017). SOCS1 regulates senescence and Ferroptosis by modulating the expression of p53 target genes. Aging (Albany N. Y) 9, 2137-2162. doi: 10.18632/aging.101306

Sandberg, M., Patil, J., D’angelo, B., Weber, S. G., and Mallard, C. (2014). NRF2regulation in brain health and disease: implication of cerebral inflammation. Neuropharmacology 79, 298-306. doi: 10.1016/j.neuropharm.2013.11.004

Selvakumar, G. P., Ahmed, M. E., Raikwar, S. P., Thangavel, R., Kempuraj, D., Dubova, I., et al. (2019). CRISPR/Cas9 editing of glia maturation factor regulates mitochondrial dynamics by attenuation of the NRF2/HO-1 dependent ferritin activation in glial cells. J. Neuroimmun. Pharmacol. 14, 537-550. doi: 10.1007/s11481-019-09833-6

Sfera, A., Bullock, K., Price, A., Inderias, L., and Osorio, C. (2018). Ferrosenescence: the iron age of neurodegeneration? Mech. Ageing Dev. 174, 63-75. doi: 10.1016/ j.mad.2017.11.012

Shimada, K., Skouta, R., Kaplan, A., Yang, W. S., Hayano, M., Dixon, S. J., et al. (2016). Global survey of cell death mechanisms reveals metabolic regulation of Ferroptosis. Nat. Chem. Biol. 12, 497-503. doi: 10.1038/nchembio.2079

Shin, C. S., Mishra, P., Watrous, J. D., Carelli, V., D’Aurelio, M., Jain, M., et al. (2017). The glutamate/cystine xCT antiporter antagonizes glutamine metabolism and reduces nutrient flexibility. Nat. Commun. 8:15074. doi: 10 . 1038/ncomms 15074

Shin, D., Kim, E. H., Lee, J., and Roh, J. L. (2018). Nrf2 inhibition reverses resistance to GPX4 inhibitor-induced Ferroptosis in head and neck cancer. Free Radic. Biol. Med. 129, 454-462. doi: 10.1016/j.freeradbiomed.2018.10.426

Shin, E. J., Han, E. J., Han, H. J., Jung, K., Heo, S. J., Kim, E. A., et al. (2019). Cytoprotective effects of an aqueous extracts from atrina pectinate meat in $\mathrm{H} 2 \mathrm{O} 2$-induced oxidative stress in a human hepatocyte. Adv. Exp. Med. Biol. 1155, 661-674. doi: 10.1007/978-981-13-8023-5_58

Song, H., Wang, M., and Xin, T. (2019). Mst1 contributes to nasal epithelium inflammation via augmenting oxidative stress and mitochondrial dysfunction in a manner dependent on Nrf2 inhibition. J. Cell. Physiol. 234, 23774-23784. doi: $10.1002 /$ jcp. 28945

Sponholz, C., Huse, K., Kramer, M., Giamarellos-Bourboulis, E. J., Claus, R. A., Kern, A., et al. (2012). Gene polymorphisms in the heme degradation pathway and outcome of severe human sepsis. Shock (Augusta, Ga.) 38, 459-465. doi: 10.1097/SHK.0b013e31826ae951

Stockwell, B. R., Friedmann Angeli, J. P, Bayir, H., Bush, A. I., Conrad, M., Dixon, S. J., et al. (2017). Ferroptosis: a regulated cell death nexus linking metabolism. Redox. Biol. Dis. Cell 171, 273-285. doi: 10.1016/j.cell.2017.09.021

Sun, X., Niu, X., Chen, R., He, W., Chen, D., Kang, R., et al. (2016a). Metallothionein-1G facilitates sorafenib resistance through inhibition of Ferroptosis. Hepatology (Baltimore, Md.) 64, 488-500. doi: 10.1002/hep.28574

Sun, X., Ou, Z., Chen, R., Niu, X., Chen, D., Kang, R., et al. (2016b). Activation of the p62-Keap1-NRF2 pathway protects against Ferroptosis in hepatocellular carcinoma cells. Hepatology 63, 173-184. doi: 10.1002/hep.28251

Tanaka, N., Ikeda, Y., Ohta, Y., Deguchi, K., Tian, F., Shang, J., et al. (2011). Expression of Keap1-Nrf2 system and antioxidative proteins in mouse brain after transient middle cerebral artery occlusion. Brain Res. 1370, 246-253. doi: 10.1016/j.brainres.2010.11.010

Tarangelo, A., Magtanong, L., Bieging-Rolett, K. T., Li, Y., Ye, J., Attardi, L. D., et al. (2018). p53 suppresses metabolic stress-induced Ferroptosis in cancer cells. Cell Rep. 22, 569-575. doi: 10.1016/j.celrep.2017.12.077

Tesfay, L., Paul, B. T., Konstorum, A., Deng, Z., Cox, A. O., Lee, J., et al. (2019). Stearoyl-CoA desaturase 1 protects ovarian cancer cells from ferroptotic cell death. Cancer Res. 79, 5355-5366. doi: 10.1158/0008-5472.CAN-19-0369

Theurl, I., Hilgendorf, I., Nairz, M., Tymoszuk, P., Haschka, D., Asshoff, M., et al. (2016). On-demand erythrocyte disposal and iron recycling requires transient macrophages in the liver. Nat. Med. 22, 945-951. doi: 10.1038/nm.4146

Tomiotto-Pellissier, F., Alves, D. R., Miranda-Sapla, M. M., de Morais, S. M, Assolini, J. P., da Silva Bortoleti, B. T, et al. (2018). Caryocar coriaceum extracts exert leishmanicidal effect acting in promastigote forms by apoptosislike mechanism and intracellular amastigotes by Nrf2/HO-1/ferritin dependent response and iron depletion: leishmanicidal effect of caryocar coriaceum leaf exracts. Biomed. Pharmacother. 98, 662-672. doi: 10.1016/j.biopha.2017.12.083
Tonelli, C., Chio, I. I. C., and Tuveson, D. A. (2018). Transcriptional regulation by Nrf2. Antioxid. Redox. Signal. 29, 1727-1745. doi: 10.1089/ars.2017.7342

Ursini, F., Maiorino, M., and Gregolin, C. (1985). The selenoenzyme phospholipid hydroperoxide glutathione peroxidase. Biochim. Biophys. Acta 839, 62-70. doi: 10.1016/0304-4165(85)90182-5

van Raaij, S. E. G., Masereeuw, R., Swinkels, D. W., and Van Swelm, R. P. L. (2018). Inhibition of Nrf2 alters cell stress induced by chronic iron exposure in human proximal tubular epithelial cells. Toxicol. Lett. 295, 179-186. doi: 10.1016/j.toxlet.2018.06.1218

Vanden Berghe, T., Linkermann, A., Jouan-Lanhouet, S., Walczak, H., and Vandenabeele, P. (2014). Regulated necrosis: the expanding network of nonapoptotic cell death pathways. Nat. Rev. Mol. Cell Biol. 15, 135-147. doi: 10. 1038/nrm3737

Wang, G. Q., Zhang, B., He, X. M., Li, D. D., Shi, J. S., and Zhang, F. (2019a). Naringenin targets on astroglial Nrf2 to support dopaminergic neurons. Pharmacol. Res. 139, 452-459. doi: 10.1016/j.phrs.2018.11.043

Wang, L., Liu, Y., Du, T., Yang, H., Lei, L., Guo, M., et al. (2019b). ATF3 promotes erastin-induced Ferroptosis by suppressing system Xc(). Cell Death Differ. 27, 662-675. doi: 10.1038/s41418-019-0380-z

Wang, M., Mao, C., Ouyang, L., Liu, Y., Lai, W., Liu, N., et al. (2019c). Long noncoding RNA LINC00336 inhibits Ferroptosis in lung cancer by functioning as a competing endogenous RNA. Cell Death Differ. 26, 2329-2343. doi: 10. 1038/s41418-019-0304-y

Wang, Q., Li, W. X., Dai, S. X., Guo, Y. C., Han, F. F., Zheng, J. J., et al. (2017). Metaanalysis of Parkinson's disease and Alzheimer's disease revealed commonly impaired pathways and dysregulation of NRF2-dependent genes. J. Alzheimer Dis. JAD 56, 1525-1539. doi: 10.3233/JAD-161032

Wang, W., Green, M., Choi, J. E., Gijón, M., Kennedy, P. D., Johnson, J. K., et al. (2019d). CD8(+) T cells regulate tumour Ferroptosis during cancer immunotherapy. Nature 569, 270-274. doi: 10.1038/s41586-019-11 $70-y$

Wang, Y., Wang, G., Tan, X., Ke, K., Zhao, B., Cheng, N., et al. (2019e). MT1G serves as a tumor suppressor in hepatocellular carcinoma by interacting with p53. Oncogenesis 8:67. doi: 10.1038/s41389-019-0176-5

Wang, Y., Yang, L., Zhang, X., Cui, W., Liu, Y., Sun, Q. R., et al. (2019f). Epigenetic regulation of Ferroptosis by $\mathrm{H} 2 \mathrm{~B}$ monoubiquitination and p53. EMBO Rep. 20:e47563. doi: 10.15252/embr.201847563

Wei, P. C., Lee-Chen, G. J., Chen, C. M., Wu, Y. R., Chen, Y. J., Lin, J. L., et al. (2019). Neuroprotection of indole-derivative compound NC001-8 by the regulation of the NRF2 pathway in Parkinson's disease cell models. Oxid. Med. Cell. Long. 2019:5074367. doi: 10.1155/2019/5074367

Wen, Q., Liu, J., Kang, R., Zhou, B., and Tang, D. (2019). The release and activity of HMGB1 in Ferroptosis. Biochem. Biophys. Res. Commun. 510, 278-283. doi: 10.1016/j.bbrc.2019.01.090

Wenzel, S. E., Tyurina, Y. Y., Zhao, J., St Croix, C. M, Dar, H. H., Mao, G., et al. (2017). PEBP1 wardens Ferroptosis by enabling lipoxygenase generation of lipid death signals. Cell 171, 628-641.e26. doi: 10.1016/j.cell.2017. 09.044

White, C., Yuan, X., Schmidt, P. J., Bresciani, E., Samuel, T. K., Campagna, D., et al. (2013). HRG1 is essential for heme transport from the phagolysosome of macrophages during erythrophagocytosis. Cell Metab. 17, 261-270. doi: 10. 1016/j.cmet.2013.01.005

Winterbourn, C. C. (1995). Toxicity of iron and hydrogen peroxide: the Fenton reaction. Toxicol. Lett. 8, 969-974. doi: 10.1016/0378-4274(95)03532-x

Xie, Y., Zhu, S., Song, X., Sun, X., Fan, Y., Liu, J., et al. (2017). The tumor suppressor p53 limits Ferroptosis by blocking DPP4 activity. Cell Rep. 20, 1692-1704. doi: 10.1016/j.celrep.2017.07.055

Yang, H.-C., Wu, Y.-H., Yen, W.-C., Liu, H.-Y., Hwang, T.-L., Stern, A., et al. (2019). The redox role of G6PD in cell growth, cell death, and cancer. Cells 8:1055. doi: 10.3390/cells8091055

Yang, W. S., SriRamaratnam, R., Welsch, M. E., Shimada, K., Skouta, R., Viswanathan, V. S., et al. (2014). Regulation of ferroptotic cancer cell death by GPX4. Cell 156, 317-331. doi: 10.1016/j.cell.2013.12.010

Ye, F., Chai, W., Xie, M., Yang, M., Yu, Y., Cao, L., et al. (2019). HMGB1 regulates erastin-induced Ferroptosis via RAS-JNK/p38 signaling in HL60/NRAS(Q61L) cells. Am. J. Cancer Res. 9, 730-739.

Yoo, S. E., Chen, L., Na, R., Liu, Y., Rios, C., Van Remmen, H, et al. (2012). Gpx4 ablation in adult mice results in a lethal phenotype accompanied by 
neuronal loss in brain. Free Radic. Biol. Med. 52, 1820-1827. doi: 10.1016/j. freeradbiomed.2012.02.043

Yuan, H., Li, X., Zhang, X., Kang, R., and Tang, D. (2016). CISD1 inhibits Ferroptosis by protection against mitochondrial lipid peroxidation. Biochem. Biophys. Res. Commun. 478, 838-844. doi: 10.1016/j.bbrc.2016.08.034

Zhang, D. D. (2006). Mechanistic studies of the Nrf2-Keap1 signaling pathway. Drug Metab. Rev. 38, 769-789. doi: 10.1080/03602530600971974

Zhang, D. D., Lo, S. C., Cross, J. V., Templeton, D. J., and Hannink, M. (2004). Keap1 is a redox-regulated substrate adaptor protein for a Cul3-dependent ubiquitin ligase complex. Mol. Cell. Biol. 24, 10941-10953. doi: 10.1128/mcb. 24.24.10941-10953.2004

Zhang, J., Chambers, I., Yun, S., Phillips, J., Krause, M., and Hamza, I. (2018). Hrg1 promotes heme-iron recycling during hemolysis in the zebrafish kidney. PLoS Genet. 14:e1007665. doi: 10.1371/journal.pgen.1007665

Zhang, K., Wu, L., Zhang, P., Luo, M., Du, J., Gao, T., et al. (2018). miR-9 regulates Ferroptosis by targeting glutamic-oxaloacetic transaminase GOT1 in melanoma. Mol. Carcinog. 57, 1566-1576. doi: 10.1002/mc.2 2878

Zhang, Y., Ding, Y., Lu, T., Zhang, Y., Xu, N., McBride, D. W., et al. (2018). Biliverdin reductase-A attenuated GMH-induced inflammatory response in the spleen by inhibiting toll-like receptor-4 through eNOS/NO pathway. J. Neuroinflamm. 15:118. doi: 10.1186/s12974-018-1155-Z

Zhang, Y., Koppula, P., and Gan, B. (2019). Regulation of H2A ubiquitination and SLC7A11 expression by BAP1 and PRC1. Cell Cycle 18, 773-783. doi: $10.1080 / 15384101.2019 .1597506$
Zhang, Y. H., Wang, D. W., Xu, S. F., Zhang, S., Fan, Y. G., Yang, Y. Y., et al. (2018). alpha-Lipoic acid improves abnormal behavior by mitigation of oxidative stress, inflammation, Ferroptosis, and tauopathy in P301S Tau transgenic mice. Redox. Biol. 14, 535-548. doi: 10.1016/j.redox.2017.11.001

Zhou, Y., Wang, X., Ying, W., Wu, D., and Zhong, P. (2019). Cryptotanshinone attenuates inflammatory response of microglial cells via the Nrf2/HO-1 pathway. Front. Neurosci. 13:852. doi: 10.3389/fnins.2019.00852

Zhu, S., Zhang, Q., Sun, X., Zeh, H. J. III, Lotze, M. T., Kang, R., et al. (2017). HSPA5 regulates ferroptotic cell death in cancer cells. Cancer Res. 77, 2064-2077. doi: 10.1158/0008-5472.can-16-1979

Zille, M., Kumar, A., Kundu, N., Bourassa, M. W., Wong, V. S. C., Willis, D., et al. (2019). Ferroptosis in neurons and cancer cells is similar but differentially regulated by histone deacetylase inhibitors. eNeuro 6:ENEURO.0263-18.2019. doi: 10.1523/ENEURO.0263-18.2019

Conflict of Interest: The authors declare that the research was conducted in the absence of any commercial or financial relationships that could be construed as a potential conflict of interest.

Copyright $\odot 2020$ Song and Long. This is an open-access article distributed under the terms of the Creative Commons Attribution License (CC BY). The use, distribution or reproduction in other forums is permitted, provided the original author(s) and the copyright owner(s) are credited and that the original publication in this journal is cited, in accordance with accepted academic practice. No use, distribution or reproduction is permitted which does not comply with these terms. 